NISTIR 8375

\title{
Mapping employee networks through the NIST Interactions Survey
}

\author{
Laura Espinal \\ Camila E. Young \\ Justyna P. Zwolak
}

This publication is available free of charge from:

https://doi.org/10.6028/NIST.IR.8375

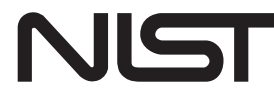

National Institute of Standards and Technology

U.S. Department of Commerce 
NISTIR 8375

\title{
Mapping employee networks through the NIST Interactions Survey
}

\author{
Laura Espinal \\ Office of the Associate Director for Laboratory Programs \\ Laboratory Programs \\ Camila Young \\ Materials and Structural Systems Division \\ Engineering Laboratory \\ Justyna P. Zwolak \\ Applied and Computational Mathematics Division \\ Information Technology Laboratory
}

This publication is available free of charge from:

https://doi.org/10.6028/NIST.IR.8375

June 2021

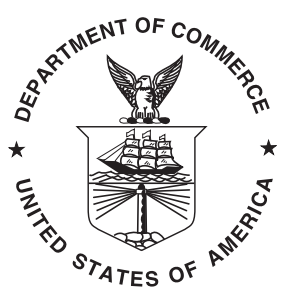

U.S. Department of Commerce Gina M. Raimondo, Secretary

National Institute of Standards and Technology James K. Olthoff, Performing the Non-Exclusive Functions and Duties of the Under Secretary of Commerce for Standards and Technology \& Director, National Institute of Standards and Technology 
Certain commercial entities, equipment, or materials may be identified in this document in order to describe an experimental procedure or concept adequately. Such identification is not intended to imply recommendation or endorsement by the National Institute of Standards and Technology, nor is it intended to imply that the entities, materials, or equipment are necessarily the best available for the purpose.

National Institute of Standards and Technology Interagency or Internal Report 8375

Natl. Inst. Stand. Technol. Interag. Intern. Rep. 8375, 62 pages (June 2021)

This publication is available free of charge from: https://doi.org/10.6028/NIST.IR.8375 


\begin{abstract}
As we begin to adopt approaches to help the U.S. National Institute of Standards and Technology (NIST) become a more inclusive organization, we need a way to assess the current level of inclusivity. The extent to which individuals have access to information and resources is largely associated with inclusion in the workplace, suggesting that analysis of individuals' social networks may be an important component of this assessment. Network surveys provide a unique lens through which a wide range of networks, including networks of collaboration, mentorship, and trust, can be studied. As a result of such studies, efforts to improve on inclusivity can be directed towards where they are needed the most. Herein, we describe the NIST Interactions Survey-a data collection tool developed for mapping and analyzing personal ego networks of NIST Federal Employees and aimed at quantifying the work- and career advice-related networks. In this study, we assess inclusivity at NIST through the lens of social network analysis to provide NIST with insights about the current work climate.

With an overall response rate of approximately $25 \%$, we find that the structure of the work- and advice-related ego networks provides important insights into the interaction patterns at NIST. An analysis of the network data confirms a siloed effect associated with the Organizational Unit affiliation of the respondents and their connections in the work and advice networks. Interestingly, we find that, while the composition of work ego networks tend to be quite aligned with what would be expected based on the workforce demographics, interactions in the advice ego networks reveal preferences associated with age and gender. In terms of gender, male employees show preference for male-dominated advice networks, which is not surprising given our predominantly male workforce. For female employees, however, we observe three distinct types of advice networks: two capturing strong preferences to seek advice from single-gender-dominated networks, be it male or female, and a third one with the gender composition quite evenly balanced. In terms of age preferences, we find that younger employees tend to seek advice from more experienced colleagues. Interestingly, no discernible differences are observed between the networks of minority and non-minority employees for either work or advice.

Based on these findings, we recommend strategies for bridging the silos between the Laboratories and the rest of the Organizational Units, nurturing informal connections among female colleagues, and mapping employee networks among different minority groups (e.g. American Indian, Asian, Black, Hispanic, Native Hawaiian, Other). Although other approaches are possible, we believe that the recommendations proposed in this report will be a good start for NIST to become the inclusive organization we aspire to be.
\end{abstract}

\title{
Key words
}

Inclusivity; diversity; employee networks; ego networks; social network analysis; homophily. 


\section{Table of Contents}

1 Introduction 1

2 Methodology 4

2.1 Survey Population and Sampling 4

2.2 Survey Development and Initial Review 5

2.3 Content and Survey Expert Reviews 6

2.4 Survey Logic and Structure $\quad 6$

2.5 Development of Survey Launching Materials 7

2.6 Survey Dissemination $\quad 7$

2.7 Workforce and Demographic Data 8

2.8 Data analysis 9

3 Results $\quad 10$

3.1 Participants Demographics and Work History 10

3.2 Ego Networks Analysis: Network Size 14

3.3 Ego Networks Analysis: Network Composition 16

3.4 Ego Networks Analysis: The Krackhardt-Stern's Index 21

4 Discussion 26

5 Conclusions $\quad 31$

6 Recommendations 33

$\begin{array}{ll}\text { References } & 37\end{array}$

Appendix A: Supplemental Materials 43 


\section{List of Tables}

Table 1 Chi square test results when comparing survey responses against the population for each attribute.

Table 2 The summary of the $\mathrm{EI}_{\mathrm{OU}}$ index distribution for the work network for all OUs.

Table A1 List of demographic and work history questions about the ego.

Table A2 List of demographic and work history questions about the alters. The same questions about each alter were asked for both Question A and B. The $N$ circulated through numbers 1 to (at most) 9. 


\section{List of Figures}

Fig. 1 The population and survey respondents distribution (Part 1). 10

Fig. 2 The population and survey respondents distribution (Part 2). 11

Fig. 3 The population and survey respondents distribution by OU. 12

Fig. 4 The demographic distribution of NIST Workforce. 13

Fig. 5 The NIST Workforce distribution by OU. 14

Fig. 6 The network size distributions.

Fig. 7 A visualization of the composition. 16

Fig. 8 The average ego network compositions in the work network for males and $\begin{array}{ll}\text { females. } & 17\end{array}$

Fig. 9 The average ego network compositions in the work network for Labs and $\begin{array}{ll}\text { Non-Labs. } & 18\end{array}$

Fig. 10 The average ego network compositions in the work network for Maryland and non-Maryland sites.

Fig. 11 The average ego network compositions in work networks for supervisors and non-supervisors.

Fig. 12 The average ego network compositions in the advice network for males and females.

Fig. 13 The average ego network compositions in advice networks for Labs and Non-Labs.

Fig. 14 The average ego network compositions in the advice network for egos from Maryland and non-Maryland.

Fig. 15 The average ego network compositions in the advice network for different age groups.

Fig. 16 A visualization of the $\mathrm{EI}_{\alpha}$ index.

Fig. 17 The $\mathrm{EI}_{\alpha}$ index distribution in the work network for location and OU. 22

Fig. 18 The $\mathrm{EI}_{\alpha}$ index distribution in the work network by OU. 23

Fig. 19 The $\mathrm{EI}_{\alpha}$ index distribution between genders. 24

Fig. 20 The $\mathrm{EI}_{\alpha}$ index distribution the advice network between age groups. 25

Fig. 21 The $\mathrm{EI}_{\alpha}$ index distribution in the advice network for location and OU. 26

Fig. A1 Network question A. $\quad 43$

Fig. A2 Network question B. 44

Fig. A3 Approval letter from the NIST Research Protections Office (Page 1 of 2). 45

Fig. A4 Approval letter from the NIST Research Protections Office (Page 2 of 2). 46

Fig. A5 Welcome page for the NIST Interactions Survey with a link to information $\begin{array}{ll}\text { sheet and brief instructions. } & 47\end{array}$

Fig. A6 Skip logic used for Question A. The same skip logic was used for Question B. 48

Fig. A7 Survey announcement.

Fig. A8 Email invitation sent to NIST Federal Employees with the link to the NIST Interactions Survey. 
Fig. A9 Final email from the NIST Director reminding staff about the NIST Interactions Survey closing soon. 


\section{Introduction}

The U.S. National Institute of Standards and Technology (NIST) seeks to promote innovation and industrial competitiveness by advancing measurement science, standards, and technology in ways that enhance economic security and improve quality of life. Inclusivity is one of the organization's four core values, along with perseverance, integrity, and excellence. NIST conceptualizes the value of inclusivity as working collaboratively to harness the diversity of people and ideas, both inside and outside of NIST, to attain the best solutions to multidisciplinary challenges [1]. Despite upholding inclusivity as one its main core values, however, recent meetings and discussions at NIST have revealed growth opportunities for this particular organizational principle. Following a 2019 Managers and Supervisors Meeting on Inclusivity [2], and two Equity Café events [3, 4], NIST's leadership team decided to launch three data-driven initiatives to better analyze and assess these growth opportunities in addressing gender as well as minority equity and inclusion [5, 6]. The intended outcome of this endeavor is to give NIST leaders the necessary insight to better inform strategies that address these deficiencies. The Inclusivity Network Analysis is one of these three initiatives. Led by Dr. Laura Espinal, the year-long study of inclusivity involved the development of a social network analysis (SNA)-based methodology to measure the degree of inclusivity at NIST.

While promoting diversity and inclusion in the federal workforce has always been important, it became even more urgent since Executive Order 13583 was signed in 2011. The executive order seeks to establish a coordinated government-wide initiative to develop equal opportunities, diversity and inclusion in the federal public sector [7]. In turn, this initiative broadly involves the development of a strategic plan, the review of applicable human resources directives, and providing guidance to agencies. The ultimate goal of the executive order is to foster a diverse and inclusive workforce through the implementation of effective recruitment and promotion practices [7]. In 2021, the Administration has prioritized equity and the importance of diversity and inclusion through executive actions, with additional agency-level guidance likely to come throughout the year.

In addition to the issues of justice and equity, promoting a diverse and inclusive workforce has demonstrated benefits as well. According to Mannix and Neale [8], the premise that diverse teams lead to more successful outcomes largely stems from the body of work focusing on heterogeneity in small groups conducted by Hoffman and colleagues [9]. One of the earlier Hoffman studies found that a multiplicity of perceptions-indicative of a heterogenous rather than homogeneous work team-can lead to more creative problemsolving [9]. Since then, a large body of work has continued lending evidence to the benefits of diverse teams. Recent research has found that diversity can be associated with producing higher quality technical and scientific outputs [10], higher research paper impact factors and citations [11], organizational innovation [12], improved team collaboration [13], and even better outcomes for healthcare patients [14].

Although most studies do support the benefits of diversity, there is also evidence that diversity can sometimes result in negative outcomes if inclusivity is not addressed [15-17]. 
While diversity can be broadly understood as the way in which members of a group differ in respect to demographic characteristics $[18,19]$ like sex, gender, and other sociocultural factors [20], inclusion refers to people's resource accessibility, group involvement, and ability to play a role in decision making $[19,21]$. A diverse and inclusive workforce can help an organization like NIST advance its mission of promoting U.S. innovation and industrial competitiveness. Indeed, existing research in this area has shown the relationship between employee diversity and innovation [22]; the literature shows there is no trade-off between diversity and quality. Relevant studies show that improving diversity can lead to higher levels of quantitative metrics of quality and innovation as evidenced by filed patent applications [23], the development of products and process innovations [24], and higher quality research publications [10]. But to reap the benefits of diversity, addressing inclusion is necessary. To that end, this project is geared towards assessing the extent of inclusivity of the NIST Workforce through the analysis of social networks.

SNA is one of the many approaches that can be implemented to study the extent to which an organization is diverse and inclusive. At a high level, SNA can be understood as a collective label that organizes concepts, theories, and techniques guided towards the study of relational data [25]. Specifically, this area of research focuses on people and the different ways in which they can relate to one another [26]. As explained by Perry and colleagues [27], SNA focuses on the structures formed by the connections between people, as well as the flow of resources and information between the different units that comprise these networks.

Other definitions of the concept highlight how SNA involves the intersection between sociology and graph theory to develop a structural description of both people and their relationships [26]. For example, Hansen, Shneiderman and Smith [28] explain that SNA leverages the principles of network science in order to explore social relationships and connections. In this context, networks are defined as a group of things and the way in which they relate to each other. The "things" that comprise a network are known in the SNA community as nodes, that is units building the network, and ties, that is relationships binding nodes. Based on the definition of nodes advanced by Perry and colleagues [27], we can come to understand that depending on the context of the study, a node can represent an individual or collective body (e.g., families, organizations, or any other entity that can form or maintain formal (e.g., legal, economic) or informal (e.g., friendship, gossip) ties. Ties, on the other hand, can represent many different types of relationships, such as proximity, collaborations, kinship, friendship, trade partnerships, citations, investments, hyperlinking, transactions, and shared attributes. A tie can be said to exist if it has some official status, is recognized by the participants, or is observed by exchange or interaction between them. A tie is any form of relationship or connection between two nodes [28]. This description of ties highlights the interdisciplinary potential of SNA. Indeed, SNA is a research technique that has been applied to a wide variety of phenomena in the many varied fields of sociology and anthropology, communication, organizational management, mathematics, and even the medical sciences [29].

Similar to the variety of interdisciplinary contexts in which SNA has been applied, 
there is also more than one SNA approach. In the context of this project, we employ what is known as ego network analysis (ENA). Like SNA, ENA is also concerned with nodes and ties that bind them. However, while the former often involves the entirety of a network structure, the latter focuses on unique subsets of the network, centered at individual nodes [30]. This variance between SNA and ENA is considered to be a methodological difference. As explained by Perry and colleagues, in whole network research, every node in the network is also a research subject whereas in ego network research, we collect data from a sample of individuals who provide information about their immediate network communities [27]. That is, ENA diverges in its focus on individually bounded personal communities rather than a common boundary applicable to all respondents.

The ego network approach focuses on representing the social network of one primary node-called the ego-and the set of nodes with direct ties to ego, called alters. As explained by Aley and Levine [30], this type of network is characterized by the central location of the ego and its links to all of the alters. Other researchers broach ego networks in a similar way, some descriptions focusing on an individual and their social ties [31]; the set of nodes that connect to the ego [32]; or the network that forms around the ego and its alters based on the relationships that bind them $[25,33]$.

ENA has been employed in a variety of contexts to study many phenomena, including, but not limited to, how young adults look for prospective career-related information [30]; whether or not the structure of online social networks mirror observed offline configurations [31]; the differences in interaction patterns between males and females in an organizational setting and its impact on perceptions of influence and promotions [34]; how people manage their personal and group communication interactions [26]; racial disparities in HIV prevalence in the U.S. [35]; how patterns of socialization affect the extent to which an individual obtains the attitudes, behaviors and knowledge needed to fully participate as an organization member [36]; how urban climate protector actors collaborate [33]; the relationship between social capital and innovation [37]; and to search for, identify, and prioritize disease subnetworks as well as gene markers from a biological network [38].

There are several reasons why SNA methodological approaches, including ENA, are appropriate to explore diversity and inclusivity at NIST. First, previous research has already demonstrated that ENA can be successfully implemented to study how people seek career-related information from the people in their networks [30]. Related specifically to diversity and inclusion, earlier SNA studies have also found evidence that women were not included in men's and/or the dominant networks [34]. In addition to gender, other ENA research has shown positive outcomes associated with having diverse and inclusive networks respective to job roles. For instance, according to one study [36], having supervisors (as opposed to just peers) within one's informational network also related to job and role learning. Together, these results support the notion that job and role learning are very different from more general organizational learning and hence have different requirements. Taken together, these studies showcase that ENA can be successfully implemented to explore and quantify the prevalence or lack of diversity and inclusion in a workplace setting. Moreover, they provide a theoretical roadmap that allows to not only contextualize this work on an 
extant body of research, but to trace the potential implications of the findings and necessary next steps.

\section{Methodology}

As we explain in the previous section, one way to assess inclusivity in a work environment is through the observance of the individuals' closest work-related interactions. Since the interaction data are relational in nature, we use SNA to examine the characteristics of the interpersonal interactions at NIST. We follow the standard SNA notation, calling all the individuals included in the network nodes and the interactions between these individuals ties. With the ego networks being the focus of our analysis, in what follows we use the term egos in reference to the individuals who responded to the NIST Interaction Survey and the term alters in reference to the individuals who were listed in response to the survey. In this study, we are interested in two types of interactions between egos and alters: (1) interactions related to achieving work-related goals at NIST, and (2) advice about careerrelated decisions at NIST. In addition to the interaction data, we incorporate into the ENA the demographic (e.g., gender, ethnicity, age group) and other (tenure, supervisory status) characteristics about the egos and alters. We use the term attributes when referring to such characteristics. The attributes for egos and alters need not be the same. Importantly, SNA (and ENA) provides the ability to combine relational data with attribute data when quantifying networks.

\subsection{Survey Population and Sampling}

In this study, the population of interest is NIST Federal Employees. Although the population of NIST Associates is an important component of our workforce, including NIST Associates as survey participants would have significantly delayed the study due to additional requirements. Thus, NIST Associates are not included in the survey population. It is important to note, however, that the intrinsically interactive nature of the relational data in SNA studies requires carefully defined network boundaries. Not including some relevant nodes or ties may affect the properties of both the entire network and those of each individual node. To ensure that the reported networks are true representations of the NIST environment, we opted to define the exogenously determined network boundaries by the status of being either a NIST Federal Employee or a NIST Associate. That is, the respondents were allowed to report NIST Associate as alters.

It is worth noting that this is the first time that NIST launched a social network survey. As such, we do not have historical response rate data from previous years for this kind of survey neither do we know the probability of getting responses from each group. Without any historical data, our study relies on a nonprobability sampling method whereby the entire population of NIST Federal Employees was invited to participate. Participation was completely voluntary. Apart from allowing us to obtain a point of reference in terms of response rates per categorical group, nonprobability sampling also allowed us to preserve 
anonymity of survey participants and thus gave us the additional advantage of launching of the survey quickly.

\subsection{Survey Development and Initial Review}

To collect social network data, a prototype online network survey was developed. Several considerations went into designing the questions that would best capture the interactions of interest among members of the NIST Workforce. In consultation with an external SNA expert, several options were considered and discussed. Ultimately, an approach for data collection was selected to match with the extended telework status at the time and the latest IT privacy policies at NIST. We decided to develop a survey that was anonymous but asked participants (egos) to provide certain demographic and work history information. Initially the survey included three network questions. To assure that both NIST Federal Employees and NIST Associates are considered as alters, the questions referred to alters are "NIST colleagues" (see, e.g., Fig. A1 in the Appendix for the exact wording of the survey questions). The survey participant did not have to provide names of their alters but only a subset of demographic information about them. Finally, the participants were asked to assess whether the connections (alters) in each network interacted with each other as well.

The first version of the survey was tested with less than nine NIST Federal Employees to gather qualitative comments about their experience taking it. This version was also reviewed by the Office of Human Resources Management (OHRM) to ensure accuracy of the terminology used in the questions and by the NIST Privacy Office to gather their input early on. Significant revisions were suggested to improve the experience. For example, the list of demographic and work history questions about the survey participant and their connections was considered very long and tiring. A reduction in the number of network questions to two was suggested as an approach to reduce the length of the survey to a more manageable size. Also, assessment of interactions between alters was considered difficult, tedious, and time-consuming.

The suggested revisions made the survey shorter and more pleasant to take. In the revised version, we reduced the number of demographic and work history attributes about the ego to seven: gender, race, age, supervisory status, tenure, location, and OU (see Table A1 in the Appendix). For the alters in the network, we reduced the number of demographic and work history attributes to five: gender, relative age (compared to self), supervisory status, location, and OU. We also removed the requirement to assess interactions between alters in the network (see Table A2 in the Appendix). Ultimately, we settled on the two network questions that reflected the two interactions of interest. The first network question (Question A) prompted the survey participant to focus on the work-related network (see Fig. A1 in the Appendix). The second network question (Question B) was focused on the career-related advice network (see Fig. A2 in the Appendix). In addition, to differentiate our survey from other surveys that had been distributed NIST-wide earlier in the year, we decided to give our survey a self-explanatory nickname that could be used during launching 
and advertising. The nickname we chose was "NIST Interactions Survey”.

\subsection{Content and Survey Expert Reviews}

Once the structure of the NIST Interactions Survey was finalized and network questions and attributes were decided on, the network questions were sent to two external content and survey experts for review. The survey experts-well-known researchers who pioneered the use of SNA in physics education research-provided detailed feedback about how well the questions addressed the interactions being sought. They also suggested that the maximum number of colleagues the respondents could list per network question should be removed from view to decrease the impression that survey respondents were expected to reach a target maximum number. In addition, the language in network Question B was modified to better reflect the career-related advice interaction of interest described in the explanatory narrative that accompanied the question itself. The argument was that respondents may not always read the entire explanatory language. After the external review, the NIST Interactions Survey was created in Google Forms where minor changes were made to make the flow of the survey fit the features available in the data collection tool and facilitate post-processing data analysis. Additional minor changes were also made as part of the NIST Research Protections Office (RPO) review, which included the review of the information sheet that accompanied the survey. For instance, when asking if a given alter was a supervisor or manager, a clarifying statement "not necessarily yours" was added to remove ambiguity. The approval letter from the NIST RPO can be found in Figs. A3 and A4 in the Appendix.

\subsection{Survey Logic and Structure}

The implementation of the NIST Interactions Survey included branching and skip logic decisions. The survey began with a welcome page that briefly explained what the survey would entail and provided a link to the information sheet [39] describing the survey in more detail (see Fig. A5 in the Appendix). In that message, participants were informed that there would be a set of demographic and work history questions about themselves. It also alerted participants that there would be two network questions. Because the survey did not ask participants to provide their names or the names of their NIST colleagues (alters), the participant were asked to get a piece of paper to write down the names that came to mind for each network question and keep track of the answers on their own.

Although there was a single version of the survey, the length of the survey was subject to the number of alters that came to mind for every participant for each of the network questions. The network questions prompted the participant to think about the names of alters and were used to define a priori the interactions of interest for our study. As such, Question A reflects respondents' work-related network and Question B reflects their careerrelated advice network. Before asking the survey participant to provide information about attributes of each of the alters, the participant was asked whether they had finished writing 
the names of the alters on a piece of paper. The reason was to encourage participants to think about names of their colleagues without knowing the attributes that would be asked.

For the work-related network, the participants were asked to think about at least three alters. In the survey the alters were labeled as generic "Person 1", "Person 2", and "Person 3". After the attributes for each of the three alters were specified, the participant was asked if they had more than three (four, five, etc.) colleagues on the list and if the answer was affirmative, they were asked about attributes for each additional alter (see Fig. A6 in the Appendix). That logic was kept until the participant answered "no" or the number of alters reached a total of nine, whichever occurred first. At that point, the participant was taken to the question about career and advice-related network. Here, there was no minimum number of colleagues (alters) required. The participants were asked if they had at least one alter in the list. If they answered "yes", the survey asked for attributes for generic "Person 1" and then the logic followed that for Question A. If the respondents did not have any alters on the list or if the number of colleagues reached a total of nine, the survey asked the participant to submit the responses representing the end of the survey.

\subsection{Development of Survey Launching Materials}

Several materials were developed to launch the NIST Interactions Survey. These included: initial email invitation, reminder emails, survey landing page text, and information sheet. A landing page was designed to provide a brief overview of the survey, the expected completion time (approximately 20 minutes), and other important details related to human subjects such as the voluntary nature of the survey, that responses would be anonymous, and that no attempt would be made to identify respondents. A required field was included on this page for a prepopulated token value that was randomly generated through the email dissemination script developed to preserve the anonymity of the survey respondents and simultaneously keep the responses to one per survey participant. Contact information and instructions were included on the landing page if the survey participant did not see a prepopulated token value. Except for the landing page, which only had a continue button, there were back and continue buttons at the bottom of each survey page. The last page in the survey had a back and a submit button.

\subsection{Survey Dissemination}

An initial message from the NIST Director was sent on October $26^{\text {th }}, 2020$ alerting NIST staff that the NIST Interactions Survey was coming soon (see Fig. A7 in the Appendix). The survey was officially launched on November $4^{\text {th }}, 2020$ with an email message from the NIST Director sent to all NIST Federal Employees who were at least 18 years old and working at NIST as of October 10 10 , 2020 (see Fig. A8 in the Appendix). To limit the number of responses to only one per participant, the email message contained a link to access the survey that was unique to every recipient. Setting up a unique URL link per survey participant was deemed essential for a number of reasons. In particular, limiting 
the number of responses to one per participant in Google forms requires the survey participants to have a Google account. Since not every NIST Federal Employee has a Google account, the requirement to create one in order to take the survey would certainly have hindered participation. In addition, asking survey respondents to fill out an anonymous survey with a Google account could come across as conflicting with the commitment to preserve anonymity of participants.

Survey dissemination via email with a unique URL link per survey participant was accomplished through a privacy-preserving script that was written, tested, and deployed with approval from the Office of Information Systems Management (OISM) Assessment and Authorization team. OISM asked us to pick an email address ending in "@ nist.gov" as the reply-to address to decrease the chance of the survey invitation landing in the junk/spam folders. Accordingly, although the survey invitation was signed by the NIST Director, the donotreply@nist.gov address was used as the sender to avoid flooding the Director's email with any potential questions, replies, and undeliverable email notices. Proper contact information was provided on the landing page of the survey as well as in the information sheet (see Fig. A5 in the Appendix). With an approval from the Public Affairs Office, the survey invitation also included a NIST banner that reflected the name of the survey (see Fig. A8 in the Appendix). Snapshots of the survey itself, including network questions and skip logic examples, can be found in Appendix A. The survey remained open for a period of three weeks. Between the launching and closing dates, an announcement was posted on the internal NIST website (inet.gov), then a reminder was sent from the Associate Directors to their leadership teams, and another from the Operational Unit (OU) Directors to their staff. A final reminder email message was sent from the NIST Director to all staff the week prior to the closing date (see Fig. A9 in the Appendix). In the last reminder, a note was added asking those who did not receive the survey to check their junk/spam folder. Regardless of the message within every reminder, all participants were directed to the original email message sent by the NIST Director on the launching date.

\subsection{Workforce and Demographic Data}

As part of the study, anonymized workforce data about NIST Federal Employees and Associates was requested. The following workforce data: gender, race, age group, supervisory status, tenure, and organizational unit (OU), was received from Office of Human Resources Management (OHRM) for NIST Federal Employees who were at least 18 years old and working at NIST as of October $10^{\text {th }}, 2020$. These data were used to obtain the distributions of the various attributes in the population of NIST Federal Employees. Similarly, the following workforce data: gender, age group, tenure, and OU, was received from the NIST Associates Information System (NAIS) for NIST Associates who were working at NIST as of October $19^{\text {th }}, 2020$. These data were used to obtain the distributions of the various attributes in the population of the entire NIST Workforce. 


\subsection{Data analysis}

To quantify the respondents' broadly defined connectivity, we use the size of the ego networks. The size of the network at the ego-level is quantified by the degree centrality measure $C$ (also called total degree). Degree is calculated as a number of ties that connect an ego with alters (or, equivalently, as the number of alters an ego has). Depending on the network question, degree can be thought of as a measure of social integration, sociability, influence, or access to resources and support, all of which can influence ego's behavior.

To capture the diversity in respondents ego networks we use the measure of network composition. Composition is calculated as fraction of alters in each possible category based on either a single alter attribute $\alpha$ or a combination of multiple attributes $\left\{\alpha_{i}\right\}_{1}^{N}$. It thus allows to quantify the overall social or demographic make up the ego network. Composition measure relies solely on alter attributes and does not take into account the ego attributes.

To assess the similarity between the ego and alters, we use the Krackhardt-Stern's $E-I$ index [40]. The E-I index is a social network measure capturing how the relative density of internal connections within a given social group compares to the number of connections that group has to the external world. It can be thought of as a measure of acculturation as it allows to quantify the outcome of two or more cultures coming into contact. For a given attribute of interest $\alpha$, the E-I index is defined as

$$
\mathrm{EI}_{\alpha}=\frac{E-I}{E+I},
$$

where $E$ is number of ties to alters in different groups according to the attribute $\alpha$ (external ties) and $I$ is number of ties to alters sharing the attribute $\alpha$. The $\mathrm{EI}_{\alpha}$ varies between -1 (indication homophily, i.e., preference for alters that share the attributes with the ego) and 1 (indicating heterophily, i.e., preference for alters that do not share the attributes with the ego).

The chi-square goodness of fit test was used to test for statistically significant differences between the NIST population and the survey respondents as a whole as well as for differences in network metrics between males and females. Since the NIST database did not include non-binary gender option and the number of respondents who reported non-binary gender was low $(N=2)$, all test comparing gender-based differences include only males and females. When one or more of the cell counts in a contingency table was less than five, the Fisher's exact test was used instead of the chi-squared test and only $p$ value is reported. All statistical analyses were done using Statistical Package for the Social Sciences [41] and the R statistical programming language [42]. We used the dplyr [43] and egor [44] packages for the network data analysis and ggplot2 [45] for network data visualizations.

To account for the false discovery rate, we implement the Benjamini-Hochberg procedure when appropriate and $p_{c o r r}$ is reported. We consider results with $p<0.001$ as significant. 


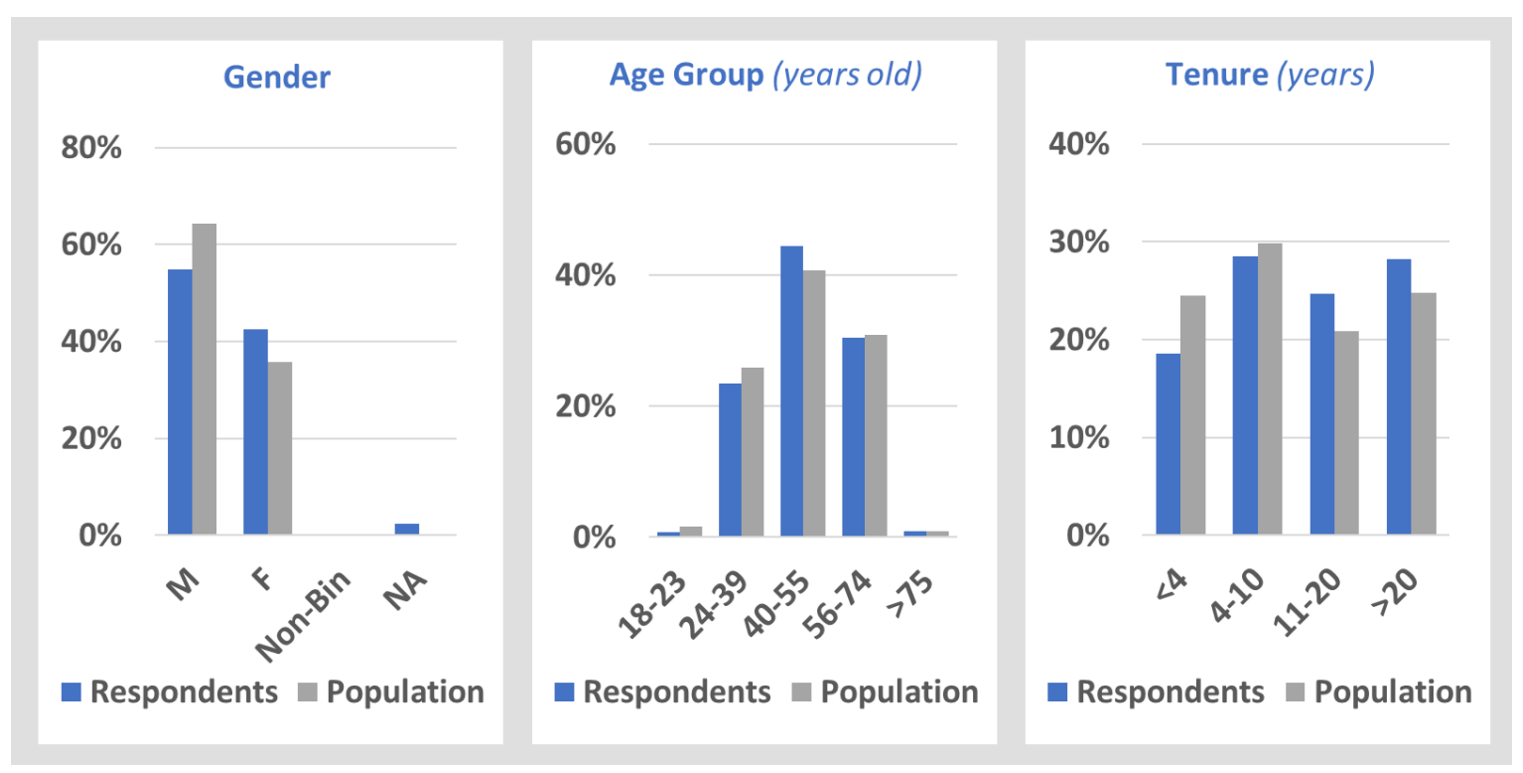

Fig. 1. The population and survey respondents distribution (Part 1). The data are categorized according to the following attributes: Gender: $M$ stands for male, F stands for female, Non-Bin stands for non-binary, and NA stands for prefer not to answer; Age group in years of age: 18-23, 24-39, 40-55, 56-74, and over 75; Tenure in years: less than 4, 4-10, 11-20, and over 20.

\section{Results}

In this section, we present the results of the analyses performed on the survey data. The survey participants data is compared against NIST Federal Employees database. Since the survey was anonymous, we cannot account for the possibility of having the same alters named in multiple networks of the same type. Thus, the NIST Workforce data (comprising both Federal Employees and Associates) is not compared against the survey.

\subsection{Participants Demographics and Work History}

For the purpose of this study, the NIST Federal Workforce data is used to define the reference distributions of attributes for the egos. Similarly, the entire NIST Workforce data (including both Federal Employees and Associates) defines the expected distributions of attributes for the alters. Out of the 3,416 employees included in the NIST Federal Workforce database, 842 completed the survey (resulting in an overall response rate of $24.6 \%$ ). Since only submitted responses were recorded, we do not have information about the number of respondents who might have started the survey but chose not to submit it.

Since all survey questions (both demographic and network-related) were mandatory, the number of participant responses $N$ was fixed for all questions. The discussion presented in this section represents the data from all 842 participants.

Figure 1 shows the percent distribution of the NIST Federal Workforce and of the survey respondents categorized according to gender, age group, and tenure. Note that while the 


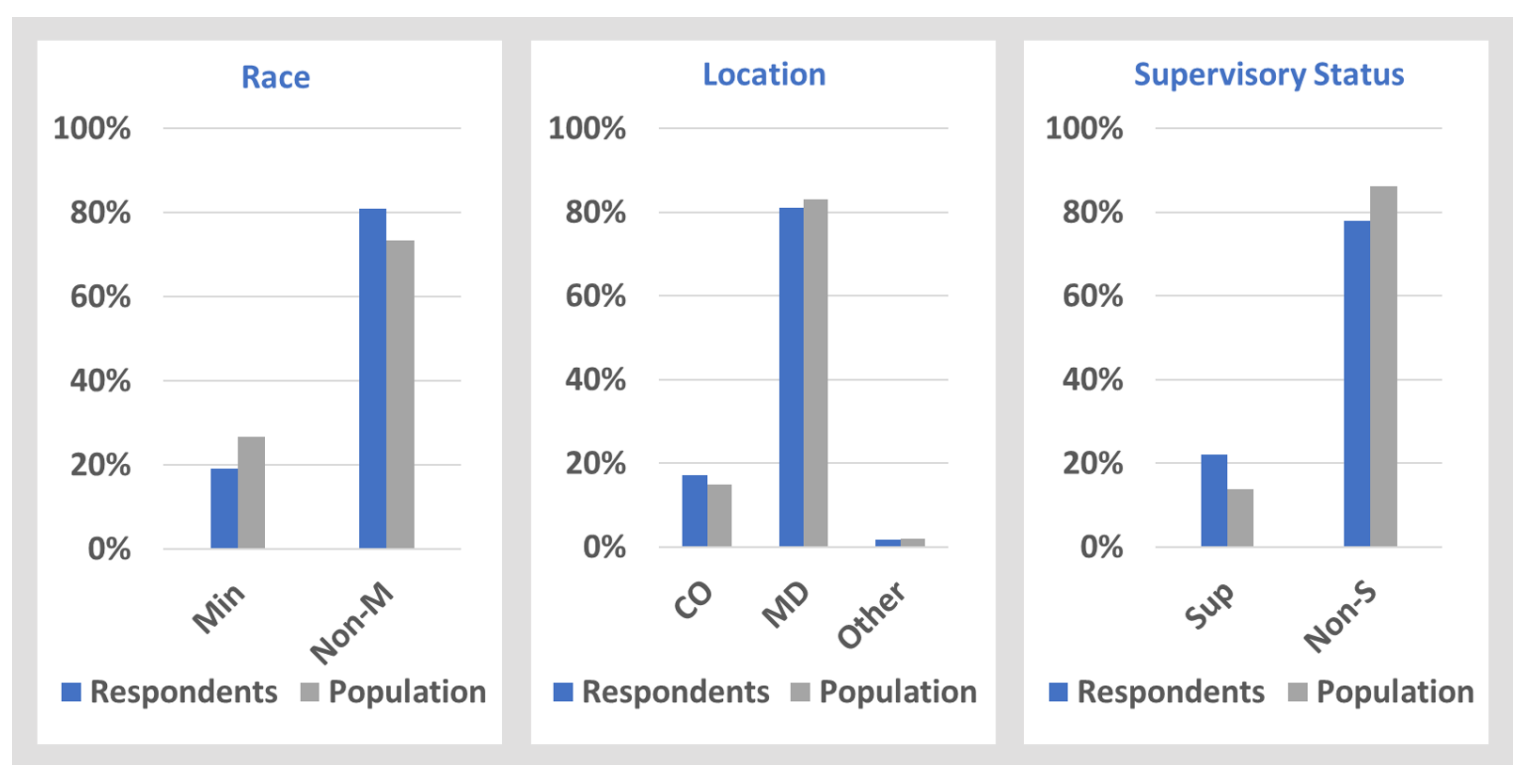

Fig. 2. The population and survey respondents distribution (Part 2). The data are categorized according to the following attributes: Race: Non-Min stands for non-minority (White) and Min stands for minority (American Indian, Asian, Black, Hispanic, Native Hawaiian, Other); Location: reflects employee's assigned duty location; Supervisory status: reflects whether the employee is a supervisor/manager or not.

survey included four gender options for the egos, including "prefer not to answer", the gender included in the workforce data is binary (male/female). The proportion of male employees (64\% of the workforce, $55 \%$ of survey respondents) is larger than that of female (36\% and $43 \%$, respectively). Among the age groups considered, the largest proportion of employees are in the age groups 24-39 (26\%), 40-55 (41\%), and 56-74 (31\%). The tenure range with the largest proportion of employees (30\%) corresponds to the range from 4 to 10 years of service with the other tenure ranges $(<4,11-20,>20)$ still over $20 \%$ each.

Figure 2 shows percent distributions for race, location, and supervisory status. Note that in this study we consider a binary race category into non-minority (White) and minority (American Indian, Asian, Black, Hispanic, Native Hawaiian, and Other). For location, we consider Colorado, Maryland, and Other. In this report, data analysis with respect to gender is limited to only male and female. Although the option was there for survey participants to select "Non-binary" or "I prefer not to answer", we received less than 25 responses combined for these categories and thus not enough to provide statistically significant conclusions. In the racial category, the largest proportion of employees are non-minority $(73 \%)$. Most of the employees play a non-supervisory role (86\%).

Of the 3,416 Federal Employees, the distribution according to directorate is as follow: $66 \%$ work in the NIST Laboratory Programs (LP), $29 \%$ work in Management Resources (MR), 3\% work in the Director's Office (DO), and 3\% work in Innovation and Industry Services (IIS). The percent distribution of survey respondents according to directorate was 


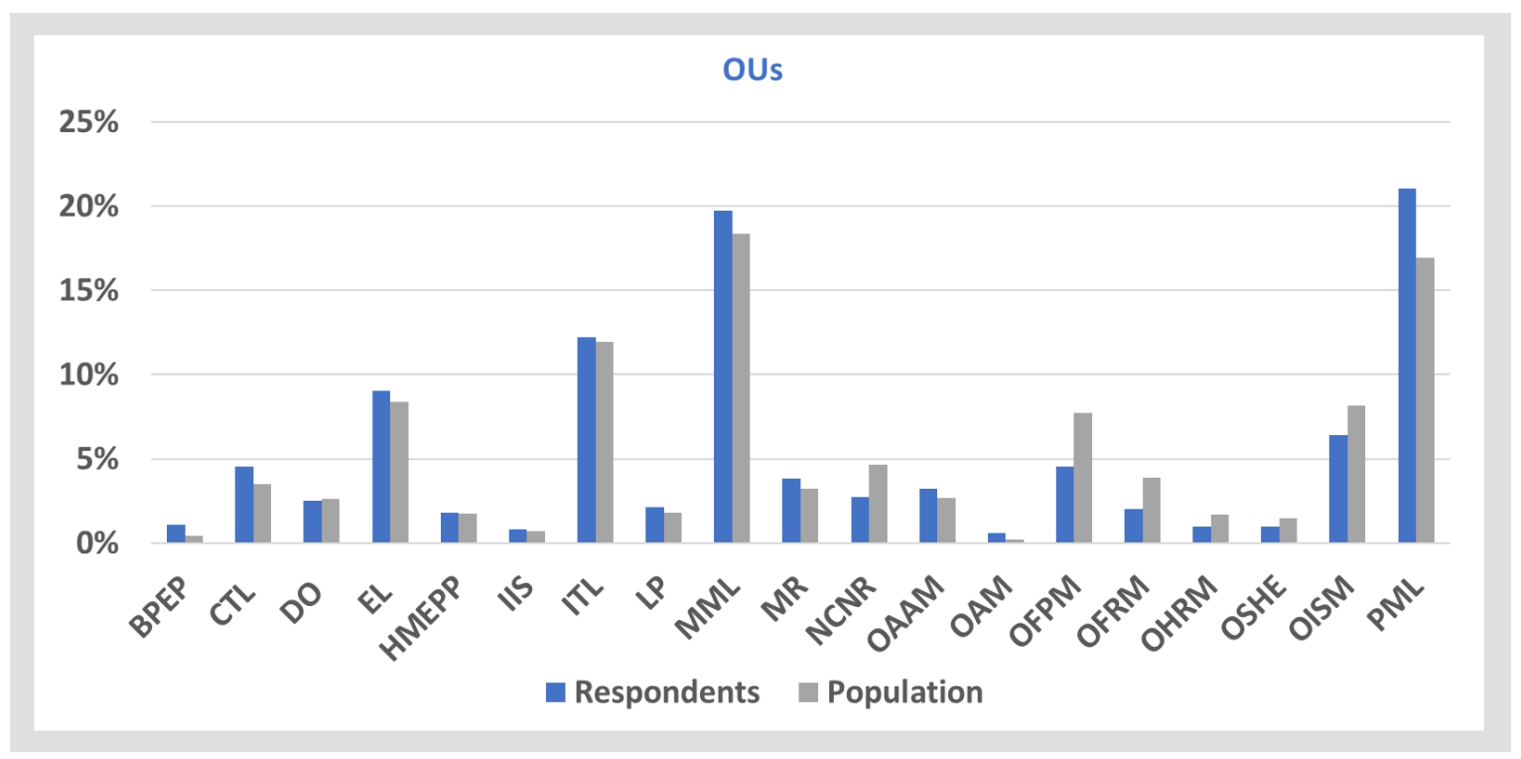

Fig. 3. The population and survey respondents distribution by OU. Percent of survey respondents compared against the population. The data are categorized according to Organizational Units.

as follow: $71 \%$ from LP, $22 \%$ from MR, $4 \%$ from IIS, and 2\% from DO. Percent distribution of the NIST Federal Workforce and of the survey respondents categorized according to Organizational Units (OU) is show in Fig. 3. For clarity, the spelling of the acronyms of the nineteen (19) OUs is listed here in alphabetical order: BPEP: Baldrige Performance Excellence Program, CTL: Communications Technology Laboratory, DO: Director's Office, EL: Engineering Laboratory, HMEPP: Hollings Manufacturing Extension Partnership Program, IIS: Innovation and Industry Services, ITL: Information Technology Laboratory, LP: Laboratory Programs, MML: Material Measurement Laboratory, MR: Management Resources, NCNR: NIST Center for Neutron Research, OAAM: Office of Acquisition and Agreements Management, OAM: Office of Advanced Manufacturing, OFPM: Office of Facilities and Property Management, OFRM: Office of Financial Resource Management, OHRM: Office of Human Resources Management, OSHE: Office of Safety, Health and Environment, OISM: Office of Information Systems Management, PML: Physical Measurement Laboratory.

To compare the distributions between NIST Federal Employees and the survey respondents all continuous attributes (e.g., age or tenure) used in our survey were broken down into well-defined clusters and treated as categorical attributes. For the 842 responses received, the chi square analysis indicated that among all the ego attributes, age and location were the only attribute for which the proportion in the sample (respondents) was equivalent to the proportions in the NIST Federal Workforce population. Table 1 summarizes the results of the test for all attributes, showing where the study sample proportions are significantly different from the population proportions across each of the different categories. 
Table 1. Chi square test results when comparing survey responses against the population for each attribute: Gender (Male, Female, Non-binary, Prefer not to answer), Age group (18-23, 24-39, 40-55, 56-74, and over 75), Tenure (<4, 4-10, 11-20, >20), Race (Non-Minority, Minority, Location (Colorado, Maryland, Other) Supervisory status (Supervisor, Non-Supervisor), and Organizational Unit.

\begin{tabular}{c|ccc}
\hline Category & $\chi^{2}$ & d.o.f. & $p$-value \\
\hline Gender & 22.1 & 1 & $<0.001$ \\
Race & 23.1 & 1 & $<0.001$ \\
Age group & 9.0 & 4 & 0.06 \\
Supervisory status & 47.5 & 1 & $<0.001$ \\
Tenure & 23.1 & 3 & $<0.001$ \\
Location & 2.9 & 2 & 0.23 \\
Organizational Unit & 60.1 & 18 & $<0.001$ \\
\hline
\end{tabular}

The demographic information for the entire NIST Workforce, which includes both Federal Employees and Associates, amounts to a total of 7,228 people. The percent distribution according to directorate is as follow: 59\% work in the NIST Laboratory Programs, 37\% work in Management Resources, $2 \%$ work in the Director's Office, $2 \%$ work in Innovation and Industry Services. A summary of demographics and work history for the entire NIST Workforce is presented in Fig. 4 and Fig. 5. Figure 4 shows the percent distribution of the entire NIST Workforce categorized according to gender, age group, and location. The racial category was not included as we only have these data for NIST Federal Employees. NAIS does not collect this information for NIST Associates. The proportion of male staff $(73 \%)$ is larger than that of female staff $(27 \%)$. The largest proportion of staff are in the age groups 24-39 (35\%), 40-55 (34\%), and 56-74 (25\%). Additionally, the proportion of non-supervisors is $93 \%$ : not shown in Fig. 4). The largest proportion of staff have been at NIST for less than 4 years (46\%; not shown in Fig. 4). The proportion of staff with

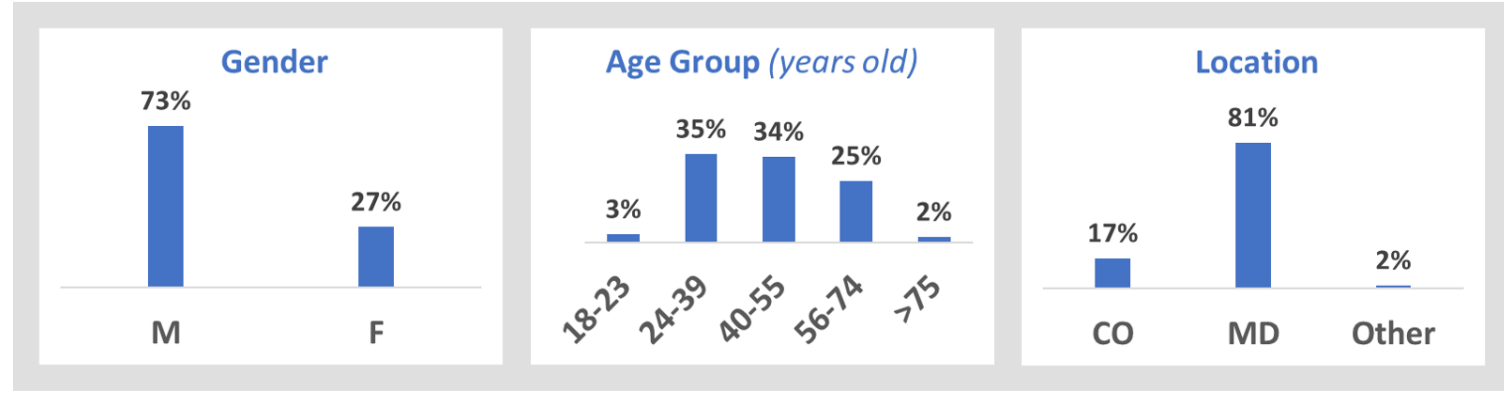

Fig. 4. The demographic distribution of NIST Workforce. The data is categorized according to the following attributes: Gender: M stands for Male, F stands for Female, Age group in years of age: $18-23,24-39,40-55,56-74$, and over 75, and Location: Reflects the assigned duty location of every employee. 


\section{OUs}

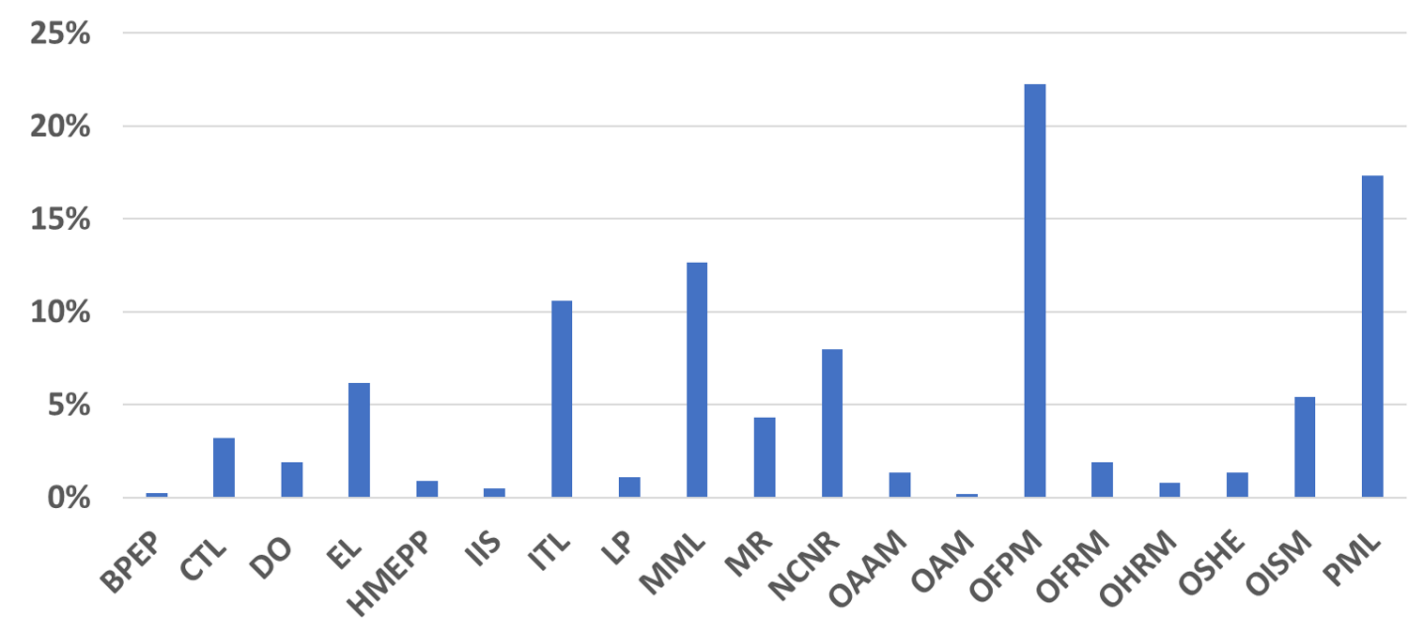

Fig. 5. The NIST Workforce distribution by OU. The data are categorized according to Organizational Units.

tenures larger than that is: 4-10 (27\%), 11-20 (15\%), >20 (12\%). The percent distribution of NIST Workforce categorized according to OUs can be found in Fig. 5. Among all the OUs, the ones with the largest proportion of staff (defined here as more than 10\%) are the following: OFPM (22\%), PML (17\%), MML (13\%), and ITL (11\%).

Since the survey was anonymous, we are not able to determine whether a given alter was listed as a connection on more than one survey response. Thus, for the purpose of our analysis, each alter listed in on the survey is treated as a distinct individual. However, while such simplification is appropriate for studying ego networks, it does not allow us to directly compare the demographics distributions between NIST Workforce and the alters.

\subsection{Ego Networks Analysis: Network Size}

The ENA was performed sequentially, with the results from one phase informing the direction and focus of the analysis in the consecutive phase. In the first phase, we performed an analysis of the ego network sizes and their variability between egos with varying sets of attributes. To capture the network size, we use the degree centrality measure. For simplicity, we use the term "work network" for the work-related network resulting from the analysis of the responses to Question A in the survey. Similarly, we use the term "advice network" for the career advice-related network resulting from the analysis of the responses to Question B in the survey.

We start our analysis by comparing the network size between respondents, using degree centrality measure $C$ as a proxy for connectivity. Without splitting the data according to gender or race, we find that the average degree for the work network is $C_{a v g}=5$ (standard deviation $S D=2$ ), approximately two times larger than that for the advice network 


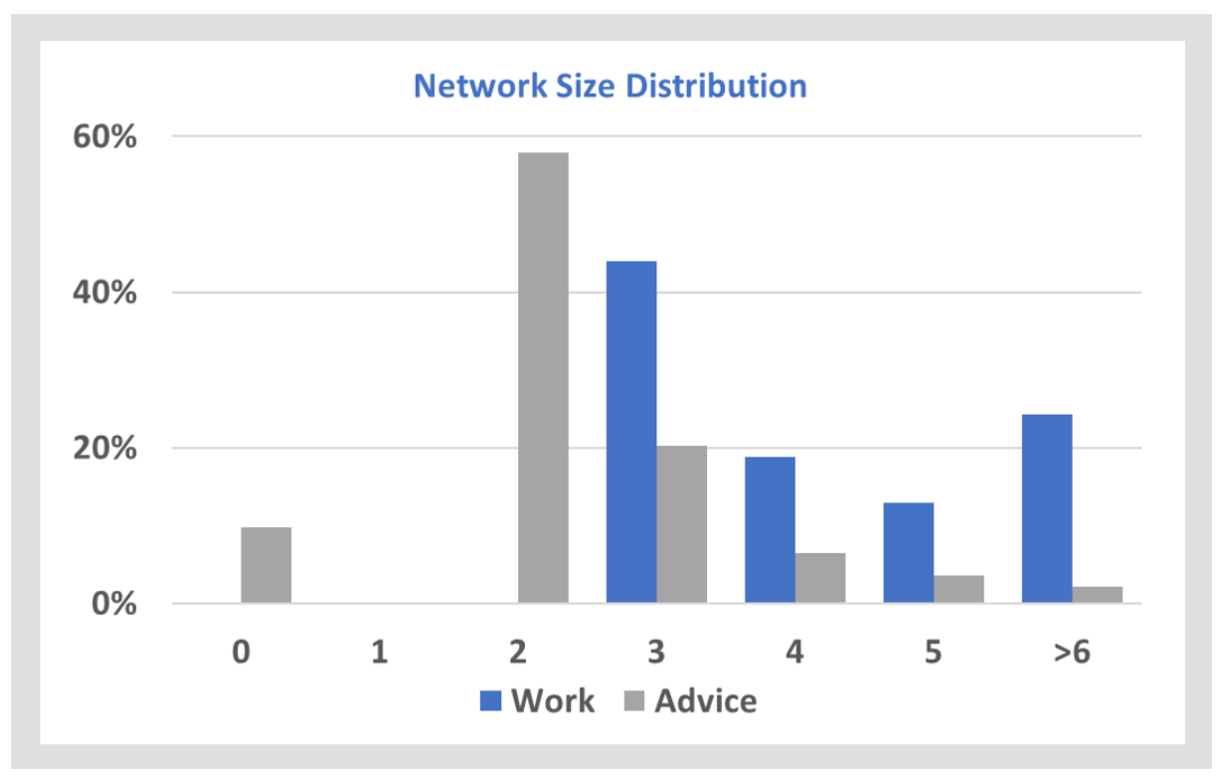

Fig. 6. The network size distributions. The distribution of network sizes categorized according to number of alters for each network: work and advice.

$\left(C_{a v g}=2, S D=1\right)$. The size distribution for both networks is presented in Fig. 6 . In the work network, we find that $43.9 \%$ respondents provided only the required 3 alters, $18.8 \%$ provided 4 alters, $12.9 \%$ provided 5 alters, and $24.3 \%$ provided more than 6 alters $(7.8 \%$ provided 6 alters, $4.4 \%$ provided 8 alters, $3.4 \%$ provided 8 alters, and $8.7 \%$ provided 9 alters). Interestingly, not a single respondent listed only one advice alter. Rather, the number of alters was either 0 (for $9.7 \%$ of respondents), or at least two, with $57.9 \%$ respondents listing 2 alters, $20.2 \%$ listing 3 alters, $6.4 \%$ listing 4 alters, $3.6 \%$ listing 5 alters, and $2.2 \%$ listing 6 or more alters. A comparison of the attributes distribution between respondents who listed no advice alters and those who listed at least two revels significant differences only based on the age group attribute, with respondents in the 56+ age groups being significantly more likely to report empty advice network than respondents in the age groups between 18 and 39 years old [ $p<0.001]$.

The work networks vary in size within the bounds (i.e., $C_{\min }=3, C_{\max }=9$ ) for males and females, regardless of ethnicity. Among respondents who chose to not report their gender the range was $C_{\min }=3$ to $C_{\max }=6(N=20)$, and for the two non-binary respondents the network size was $C=5$ and $C=6$. The average degree among non-minority respondents regardless of gender was $C_{a v g}=4(S D=2)$ and among the minority respondents $C_{a v g}=5$ $(S D=2)$, also regardless of gender. We find no statistically significant differences in the distribution of the work network size when the data is sliced by any of the ego attributes $\left[\chi^{2}(5)=9.8, p=0.08\right.$ for gender; $\chi^{2}(5)=5.2, p=0.37$ for ethnicity; $p=0.06$ for the age groups; $\chi^{2}(5)=11.2, p=0.05$ for the supervisory status; $\chi^{2}(15)=24.3, p=0.06$ for tenure; $p=0.61$ for location; and $p=0.03$ for $\mathrm{OU}]$.

As mentioned earlier, for the advice networks, there was no minimum required alters 
though the maximum number of alters was still set at nine. The resulting networks vary in size from $C_{\min }=0$ to $C_{\max }=9$. There is also more variability in the total size of networks by gender and ethnicity. For females, the network size varies from $C_{\min }=0$ to $C_{\max }=9$, regardless of ethnicity. For non-minority men, the network size ranges from $C_{\min }=0$ to $C_{\max }=8$ and for minority males the range is $C_{\min }=0$ to $C_{\max }=5$. Among respondents who chose to not report their gender the range was $C_{\min }=0$ to $C_{\max }=2$ for the non-minority group and $C_{\min }=0$ to $C_{\max }=4$ for the minority group. Both non-binary respondents reported advice networks of size $C=2$. The average degree was found to be $C_{a v g}=2(S D=$ 1) for all respondents except for the non-minority females and non-minority respondents who chose not to report their gender (here the average degree was $C_{a v g}=3, S D=1$ ). This consistency of average degree between groups suggest that the larger advice networks are rather unusual and might be treated as statistical outliers. A side-by-side size comparison confirms that only $1.8 \%$ non-minority males, $3.3 \%$ of non-minority females , and $2.3 \%$ on minority females reported advice networks larger than 5. Like for work networks, we found no significant differences in the distributions of advice network sizes for any of the attributes $[p=0.17$ gender; $p=0.82$ for ethnicity; $p=0.09$ for the age groups; $p=0.02$ for the supervisory status; $p=0.06$ for tenure; $p=0.03$ for location; $p=0.30$ for $\mathrm{OU}]$.

\subsection{Ego Networks Analysis: Network Composition}

In this phase, we look at the ego network compositions. The composition analysis allows us to quantify how diverse, on average, ego networks are. A depiction of the composition is presented in Fig. 7. A donut chart design (essentially a pie chart with the center area cut out) was chosen to represent the attribute composition of alters connected to an ego (comprising only NIST Federal Employees) as described in the center area of the donut. The donut charts shown in Fig. 7 represent a comparison of the network compositions between egos divided according to hypothetical ego-attribute that can take one of two possible values: type A (left) and type B (right). The composition here captures a hypothetical alter-attribute (binary color preference: Green or Blue).
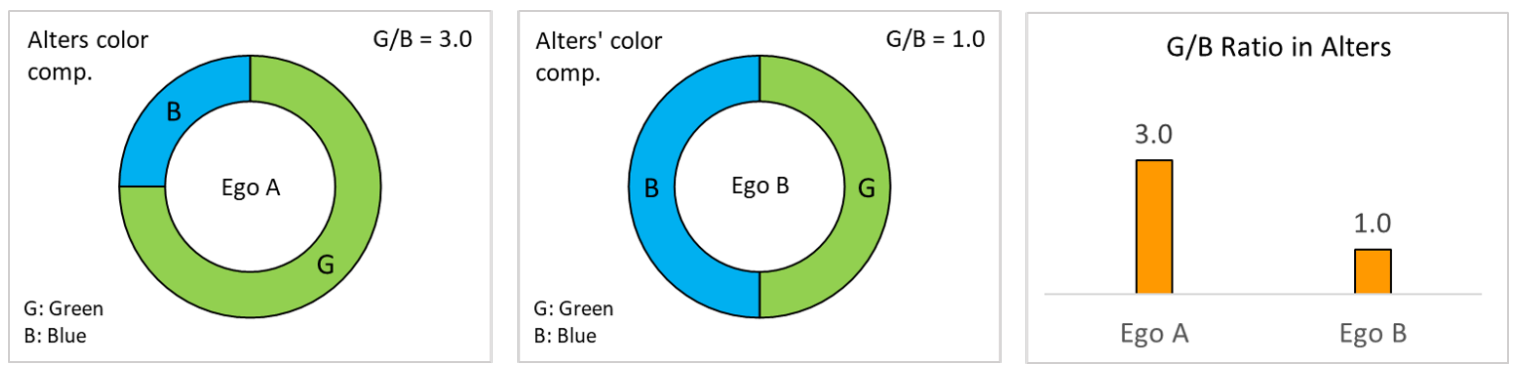

Fig. 7. A visualization of the composition. A comparison of alters' composition between the networks of two generic ego types: ego type A (left) and ego type B (right). The donut chart indicates the percent of connections that have green and blue membership as well as the Green-to-Blue (G/B) ratio for each ego network type. 

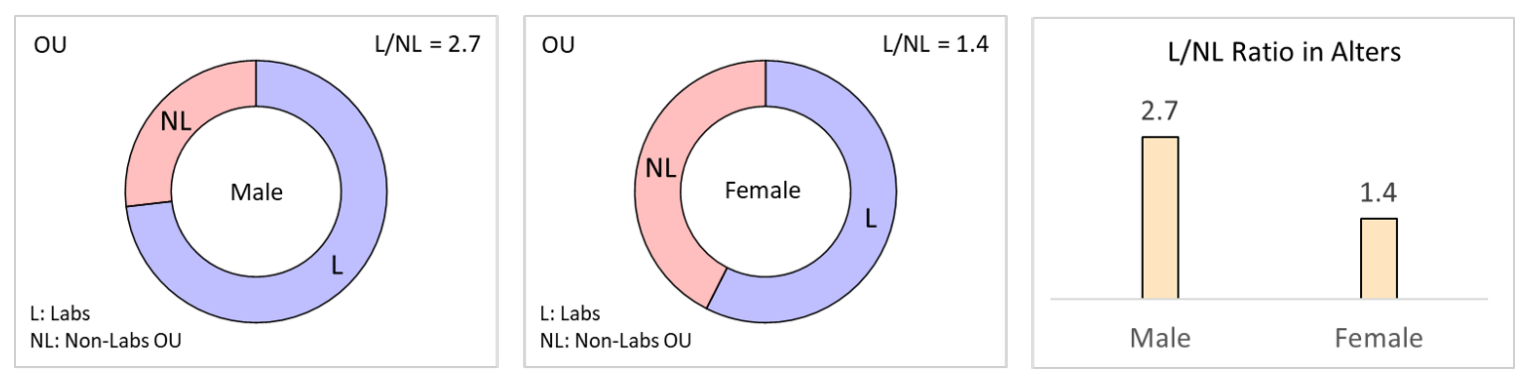

Fig. 8. The average ego network compositions in the work network for males and females. Comparison of the work networks composition based on alters' binary OU affiliation (i.e., Labs vs. Non-Labs).

While only alter attributes are used to find the composition, ego attributes can be used to compare compositions between different groups (e.g., males vs. females, supervisors vs. non-supervisors, etc.). Since the analysis from the previous phase did not reveal any differences between the various demographic groups based on the network sizes, we opt to carry the composition analysis based on all ego attributes and all alter attributes.

To assure the validity of statistical tests used to compare groups, some of the attribute options are combined prior to the analysis. In particular, as we discussed in Sec. 3.1, majority of the egos and alters reported for both networks are male or female, with less than $1 \%$ identified as non-binary and about $2 \%$ opting to not provide gender. Thus, for gender we compare compositions only between male and female egos. The ego age groups are combined into three bins: $18-39,40-55$, and $56+$. The tenure attribute is combined into two bins: less than 10 years and more than 10 years. For location, we compare between Maryland and non-Maryland egos and for OUs we consider OUs under the laboratory programs (including CTL, EL, ITL, MML, NCNR, and PML; called in what follows "Labs") and non-laboratories (including all remaining OUs; called "Non-Labs"). All $p_{\text {corr }}$ values reported in this section are adjusted following the Benjamini-Hochberg procedure.

In addition to analysis and visualization based on all groups in the given category, we also include discussion that involves the relative ratios for the alter attributes. For the attributes treated as binary, i.e., gender, supervisory status, location, and OU, we consider the male-to-female (M/F), supervisor-to-nonsupervisor ( $\mathrm{Su} / \mathrm{NSu})$, Maryland-to-nonMaryland (M/NM), and Labs-to-Non-Labs (L/NL) ratios, respectively. When more than two options are possible (e.g., for age groups), we consider the similar-to-different (S/D) ratio.

For the work network, we find five ego-alter attributes combination with statistically significant differences between groups. Composition based on alters' OU affiliation turned out to be a significant factor in three cases: when comparing between egos based on gender, $\mathrm{OU}$, and location. When comparing between genders, as shown in Fig. 8, we find that males tend to report significantly more connections with alters from Labs than females do $\left[\chi^{2}(1)=24.1, p_{\text {corr }}<0.001\right]$. Figure 9 shows a comparison of the average ego network compositions in the work network for egos from Labs and Non-Labs. Note that here we consider three possible bins for alters' OU: same as ego, different than ego (Lab), and 

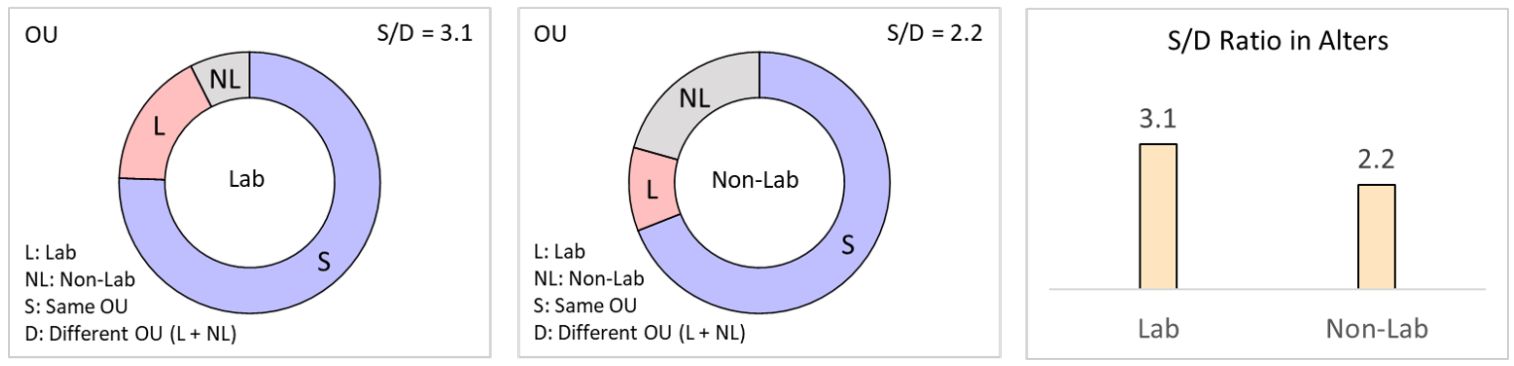

Fig. 9. The average ego network compositions in the work network for Labs and Non-Labs. Comparison of the work networks composition based on alters' OU affiliation: same as ego, different than ego (lab), and different than ego (non-lab).

different than ego (Non-Lab).

We find that even when accounting for preferences to interact with one's own OU, egos from Lab report interaction with significantly more Lab employees than Non-Lab egos $\left[\chi^{2}(2)=45.8, p_{\text {corr }}<0.001\right]$. When comparing between sites, we find that egos from Maryland tend to report significantly more ties with Labs than egos from other sites $\left[\chi^{2}(1)=19.9, p_{\text {corr }}<0.001\right]$, see the top panel in Fig. 10. Maryland egos also tend to report significantly more work-related interactions with alters from Maryland than from other sites $\left[\chi^{2}(1)=22.4, p_{\text {corr }}<0.001\right]$, see the bottom panel in Fig. 10. Finally, when
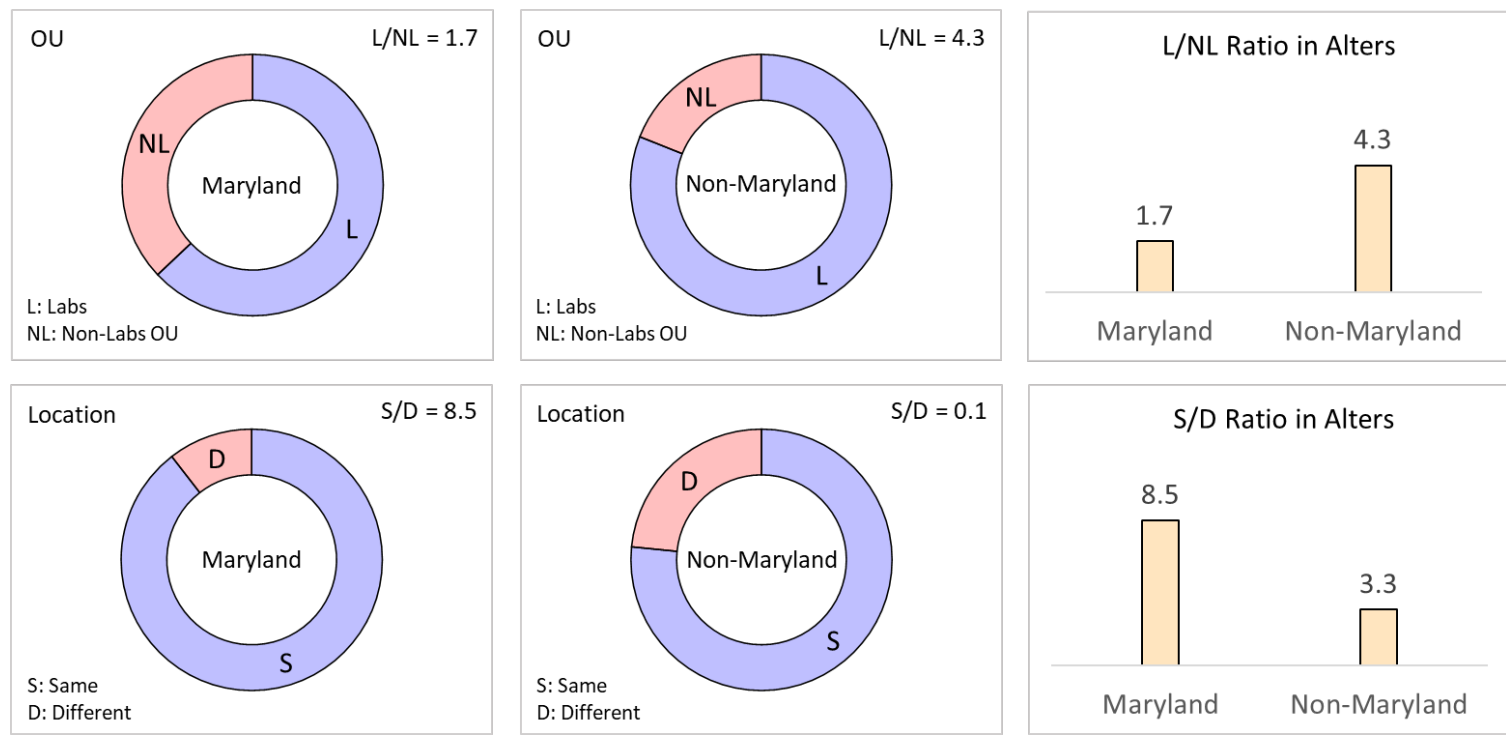

Fig. 10. The average ego network compositions in the work network for Maryland and non-Maryland sites. The top panel shows the work networks composition based on alters' binary OU affiliation (i.e., Labs vs. Non-Labs). The bottom panel shows composition based on alters' location. While the composition is calculated based on all three options (i.e., Maryland, Colorado, and Other), we opted to bin together the non-Maryland sites as only $2 \%$ of respondents declared location different than Maryland or Colorado. 

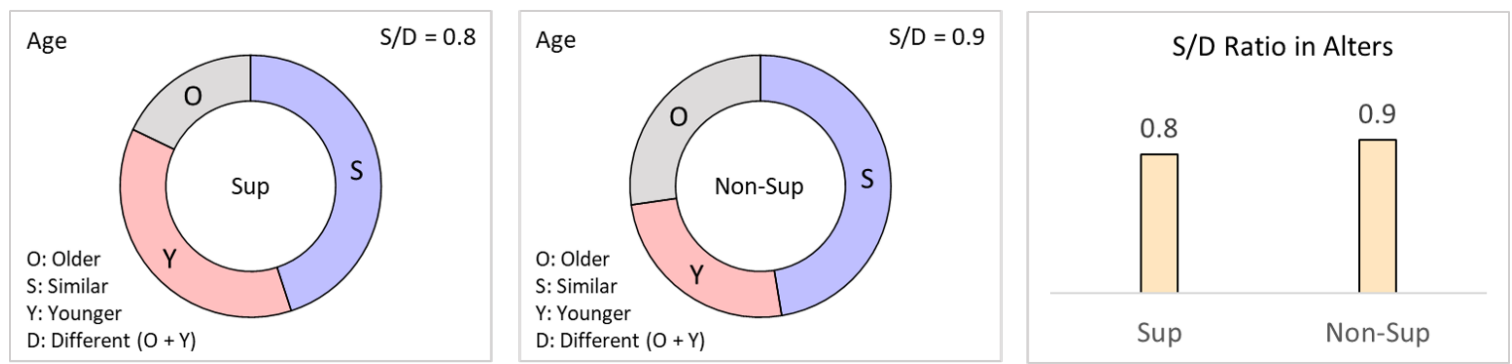

Fig. 11. The average ego network compositions in work networks for supervisors and non-supervisors. Comparison of work networks composition based on alters' age group.

comparing network composition between supervisor and non-supervisor egos, as shown in Fig. 11, we find that supervisors tend to report significantly more work-related interactions with younger alters than non-supervisors do $\left[\chi^{2}(2)=23.9, p_{\text {corr }}<0.001\right]$.

The situation is somewhat different for advice networks. Here, we find six ego-alter attributes combination with statistically significant differences between groups. Like with the work networks, composition based on alters' OU affiliation turned out to be a significant factor in three cases: for composition based on alters gender, OU, and location. The OU based composition, shown in top panel in Fig. 12, reveals that like in the work networks, males report significantly more interactions with alters from Labs than females do $\left[\chi^{2}(1)=\right.$ 19.7, $\left.p_{\text {corr }}<0.001\right]$. The overall composition is also quite consistent with work networks, with L/NL ratio of 2.8 for males (2.7 for the work network) and of 1.4 for females (same as for work network). The comparison of the average ego network composition based on
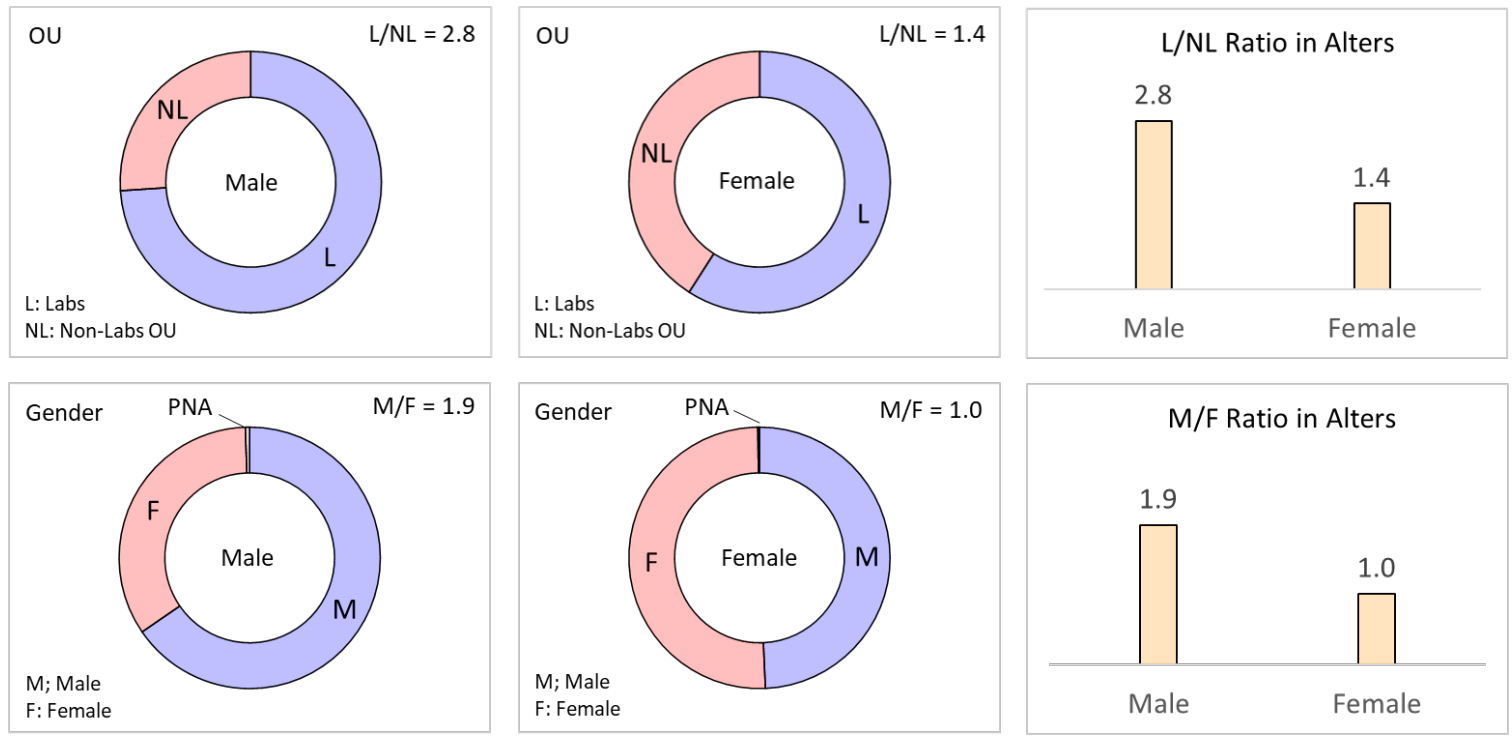

Fig. 12. The average ego network compositions in the advice network for males and females. The top panel shows the advice network composition based on alters' binary OU affiliation (i.e., Labs vs. Non-Labs). The bottom panel shows advice network composition based on alters' gender. 

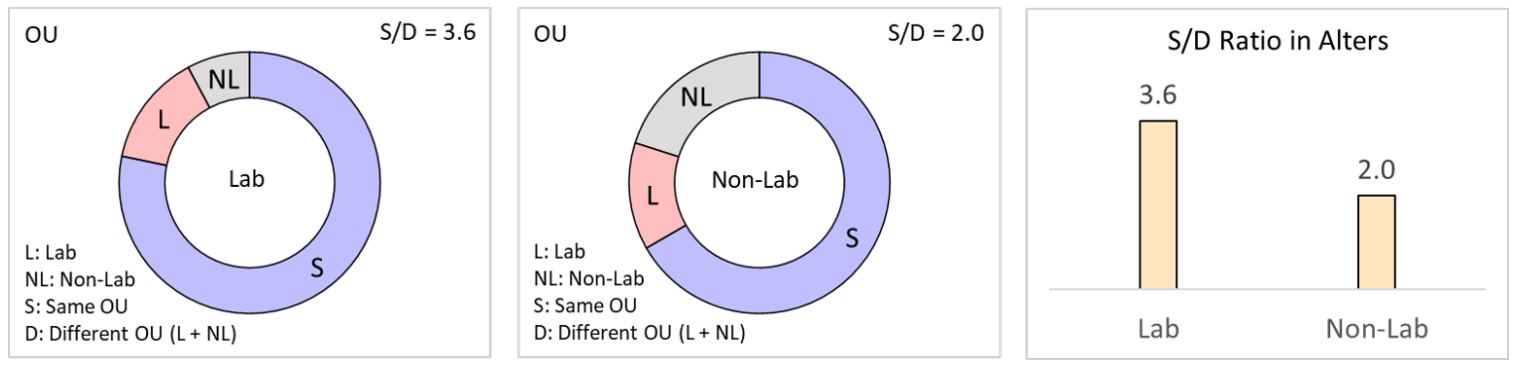

Fig. 13. The average ego network compositions in advice networks for Labs and Non-Labs. Comparison of advice networks composition based on alters' OU affiliation: same as ego, different than ego (Lab), and different than ego (Non-Lab).

gender, presented in bottom panel in Fig. 12, shows that males report significantly more interactions with male colleagues than females $\left[\chi^{2}(1)=27.8, p_{\text {corr }}<0.001\right]$.

Figure 13 shows comparison of the average advice network compositions for egos from Labs and Non-Labs. We find that both the preferences to interact with one's own OU (as captured by the S/D ratio) and preferences of egos from Lab to interact with other Lab colleagues $\left[\chi^{2}(2)=29.9, p_{\text {corr }}<0.001\right]$ are consistent with the work network. The composition comparison between sites, as shown in Fig. 14, is also quite consistent with the work network. Like before, we find that egos from both Maryland and Non-Maryland tend to report significantly more interactions with Labs than Non-Labs $\left[\chi^{2}(1)=19.8\right.$, $\left.p_{\text {corr }}<0.001\right]$, see the top panel in Fig. 14. The preference of egos from Maryland to
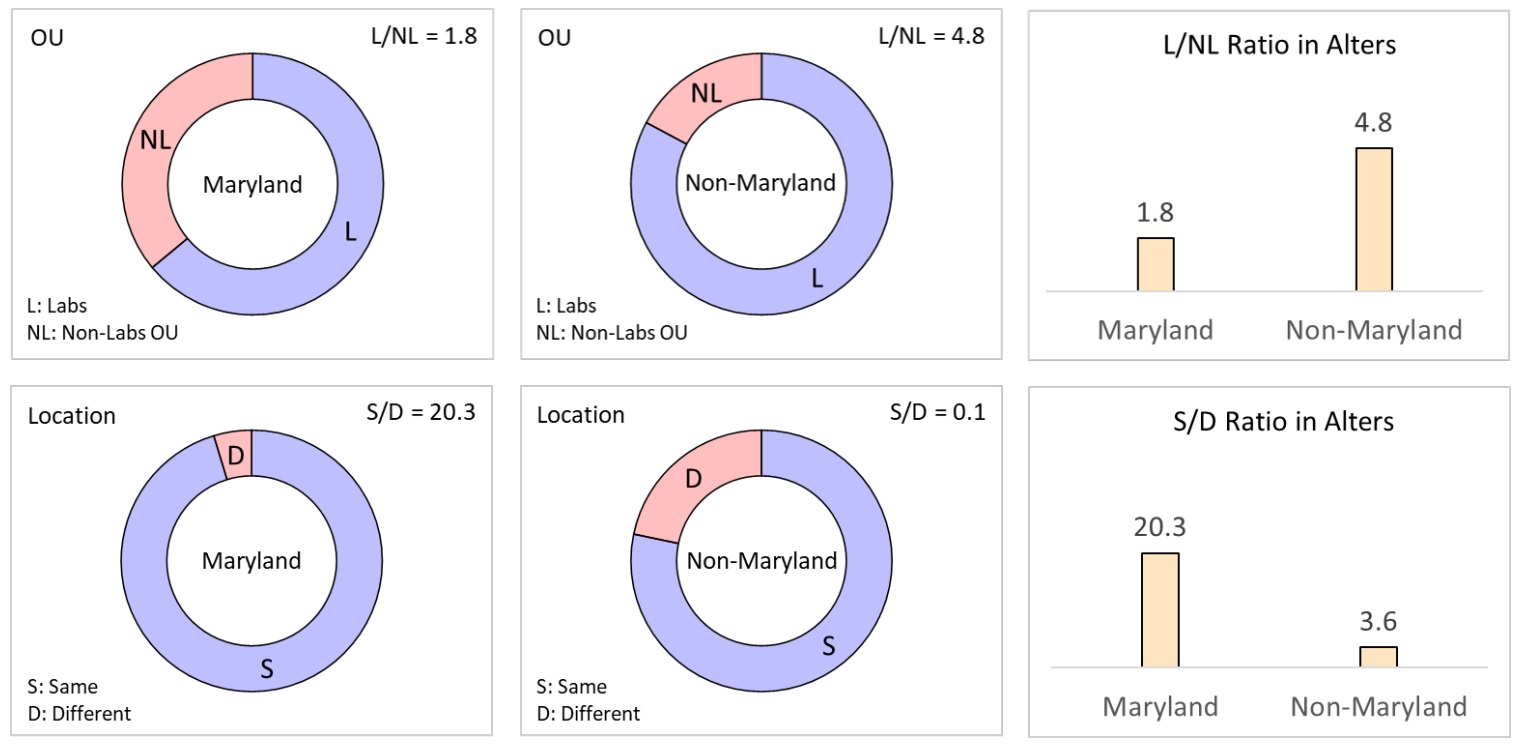

Fig. 14. The average ego network compositions in the advice network for for egos from Maryland and non-Maryland. The top panel shows the advice networks composition based on alters' binary OU affiliation (i.e., Labs vs. Non-Labs). The bottom panel shows composition based on alters' location. 


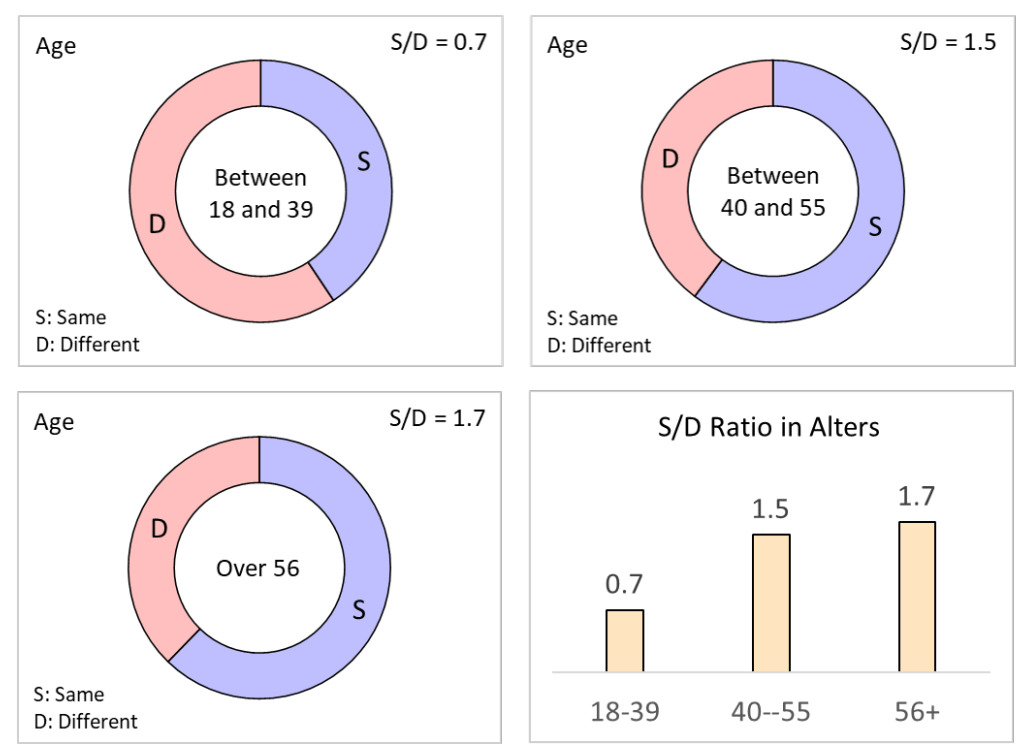

Fig. 15. The average ego network compositions in the advice network for different age groups. Comparison of the advice networks composition based on alters' age group.

seek advice from alters from Maryland than from other sites is also consistent with work network $\left[\chi^{2}(1)=49.8, p_{\text {corr }}<0.001\right]$, see the bottom panel in Fig. 14 .

Interestingly, we do not find any significant differences for the advice network based on alters supervisory status or tenure. Instead, when comparing network composition between egos from different age groups, as shown in Fig. 15, we find that egos in the 18-39 age group tend to report significantly more advice-related interactions with alters in different age groups than egos older than $40\left[\chi^{2}(2)=33.6, p_{\text {corr }}<0.001\right]$.

\subsection{Ego Networks Analysis: The Krackhardt-Stern's Index}

In the third phase of the analysis, we use the Krackhardt-Stern's $\mathrm{EI}_{\alpha}$ index to better understand the network composition. $\mathrm{The}_{\alpha} \mathrm{EI}_{\alpha}$ index is a measure of the extent to which the ego interacts with alters similar to or different from self, with values varying between $\mathrm{EI}_{\alpha}=-1$ to indicate homophily (i.e., preference to interact with alters similar to ego with respect to the attribute $\alpha$ ) alters and $\mathrm{EI}_{\alpha}=1$ to indicate heterophily (i.e., preference to interact with alters different from ego based on the attribute $\alpha$ ). Figure 16 shows a depiction of the $\mathrm{EI}_{\alpha}$, with $\alpha$ denoting preference for green shirts, for three toy networks.

The analysis in this phase for both types of ego networks (i.e., work and advice) is done according to attributes for which we previously found significant differences between groups. Since the Krackhardt-Stern's index requires that information about a given attribute $\alpha$ is available for both egos and alters, for the work network we compare the $\mathrm{EI}_{\alpha}$ between locations and OUs while for the advice network we compare between genders, age groups, locations, and OUs. To better assess the role of a given attribute in relationship building, for each attribute we provide a reference $\mathrm{EI}_{\alpha}^{r e f}$ established based on the NIST Workforce 

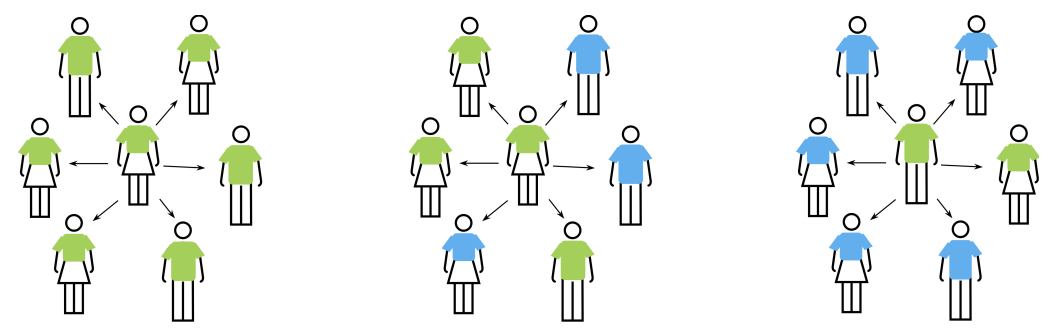

Fig. 16. A visualization of the $\mathrm{EI}_{\alpha}$ index. A comparison of the the $\mathrm{EI}_{\alpha}$, with $\alpha$ indicating preference for wearing green shirts, between three toy networks. For the left network $\mathrm{EI}_{\text {green }}=-1$, indicating strong preference for green shirts (homophily); for the central network $\mathrm{EI}_{\text {green }}=0$, indicating no shirt color preference; for the right network $\mathrm{EI}_{\text {green }}=0.7$, indicating rather strong preference for non-green shirts (heterophily).

population. Note that the $\mathrm{EI}_{\alpha}^{r e f}$ is included for reference only and should not be interpreted as indicating a preferred or target $\mathrm{EI}_{\alpha}$.

The location distribution of the NIST Workforce is $16.9 \%$ in Colorado, $81.4 \%$ in Maryland, and $1.7 \%$ at other sites. This translates to $\mathrm{EI}_{\mathrm{CO}}^{\text {ref }}=0.67, \mathrm{EI}_{\mathrm{MD}}^{r e f}=-0.63$, and $\mathrm{EI}_{\text {other }}^{\text {ref }}=0.97$ (see Eq. 1). The comparison of the $\mathrm{EI}_{\text {location }}$ index distribution between the different sites is shown in the left plot in Fig. 17. The $\mathrm{El}_{\text {location }}^{\text {ref }}$ is included in each plot as a dashed line. As we already stressed, all of the $\mathrm{EI}_{\alpha}^{r e f}$ are calculated based on the population and thus do not take into account the natural preference or convenience of interactions with alters located in close physical proximity. Thus, as expected, the actual $\mathrm{EI}_{\text {location }}$ significantly deviates from the $\mathrm{EI}_{\text {location }}^{r e f}$. Rather, there is a clear difference between the three locations that correlates with the size of the site, with Maryland site being the most homophilic $\left(\mathrm{EI}_{\mathrm{MD}}^{\text {avg }}=-0.94, S D=0.18\right)$ and the "Other" location the least homophilic $\left(\mathrm{EI}_{\text {other }}^{\text {avg }}=-0.46\right.$,
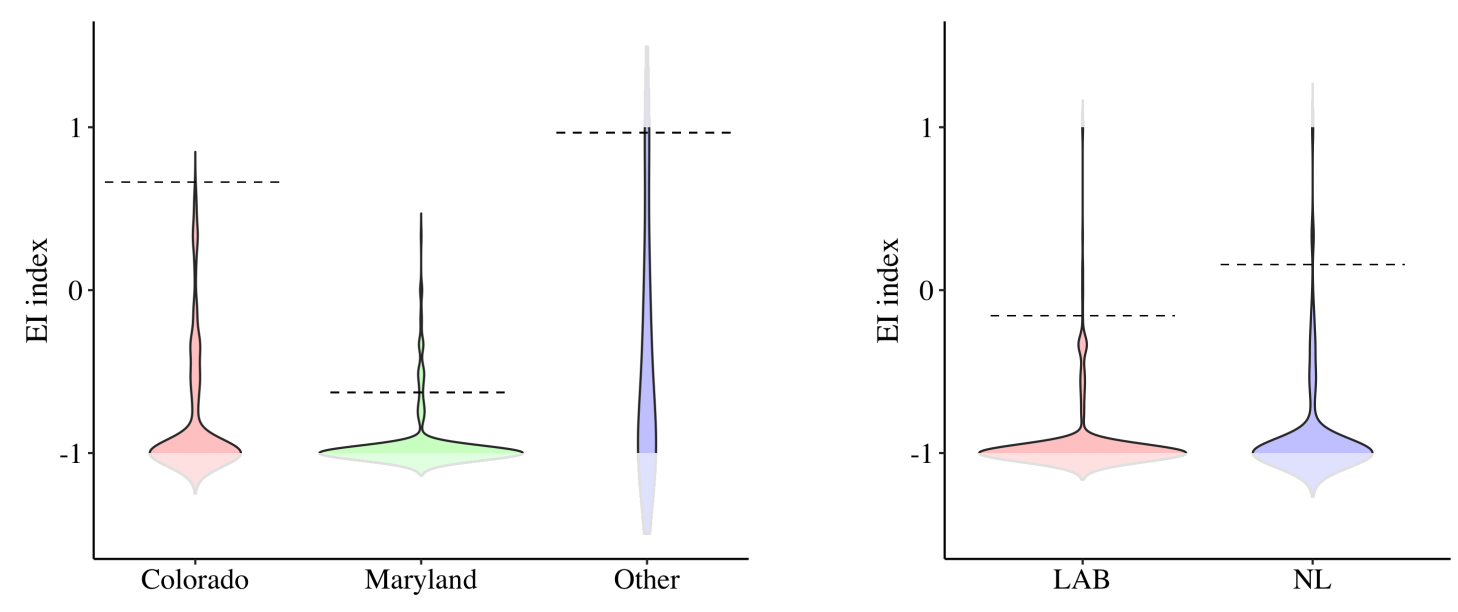

Fig. 17. The $\mathrm{EI}_{\alpha}$ index distribution in the work network for location and $\mathrm{OU}$. The left plot shows comparison of the $\mathrm{EI}_{\alpha}$ based on egos locations and the right plot based on egos' binary (i.e., Labs vs. Non-Labs) OU affiliation. 


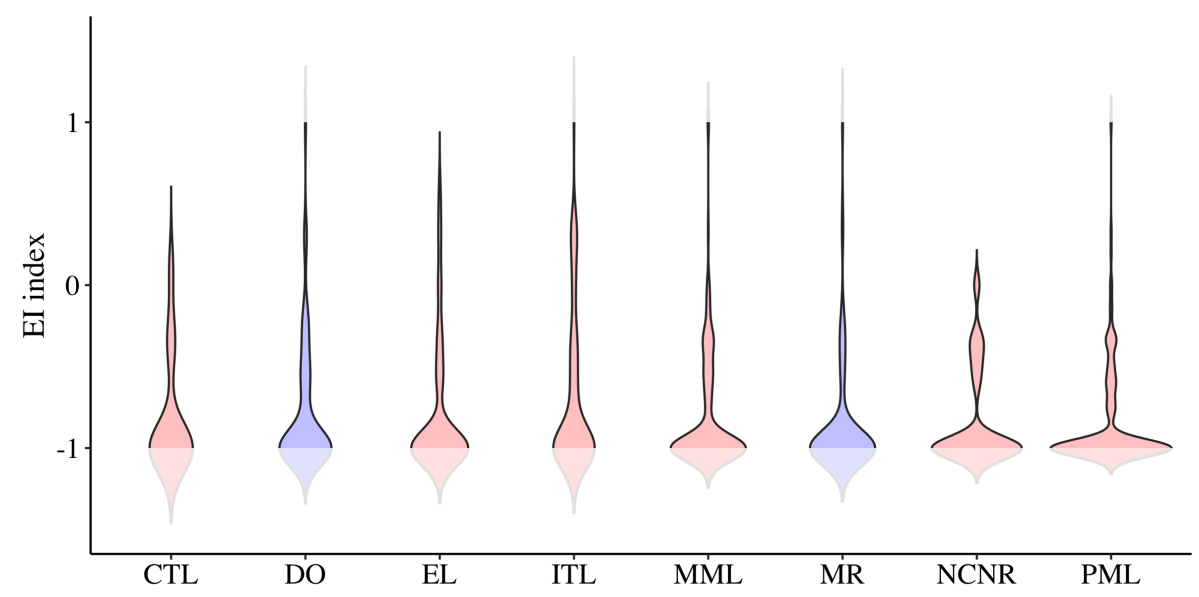

Fig. 18. The $\mathrm{EI}_{\alpha}$ index distribution in the work network by $\mathrm{OU}$. The red color indicates Lab OUs and the blue color indicates Non-Lab OUs. In this figure, DO and MR are defined as follows: DO includes the following Non-Lab OUs: DO, LP, IIS, BPEP, HMEPP, OAM; MR includes the following Non-Lab OUs: MR, OAAM, OFPM, OFRM, OHRM, OSHE, and OISM.

$S D=0.73)$. Egos from Colorado, with $\mathrm{EI}_{\mathrm{CO}}^{a v g}=-0.79(S D=0.4)$, also lean towards homophilic networks. Overall, for all locations the networks are much more homophilic than would be expected based on the available population, with the $\mathrm{EI}_{\text {location }}^{\text {med }}=-1$ for all sites.

The $\mathrm{EI}_{\mathrm{OU}}$ distribution is shown in the right plot in Fig. 17. Since the NIST Workforce is fairly equally divided between Labs (57.9\% of employees and associates) and Non-Labs ( $42.1 \%$ of employees and associates), the $\mathrm{EI}_{\mathrm{OU}}^{r e f}$ is relative close to 0, with $\mathrm{EI}_{\mathrm{LAB}}=-0.16$ and $\mathrm{EI}_{\mathrm{NL}}=0.16$. The real work networks, however, tend to be much more homophilic, with egos in both Labs and Non-Labs reporting interacting mostly with alters from the same type of $\mathrm{OU}\left(\mathrm{EI}_{\mathrm{LAB}}^{a v g}=-0.94, S D=0.22 ; \mathrm{EI}_{\mathrm{NL}}^{a v g}=-0.9, S D=0.3\right)$. As shown in Fig. 18, there is in fact a strong preference for interactions with alters from ones own OU.

Table 2. The summary of the $\mathrm{EI}_{\mathrm{OU}}$ index distribution for the work network for all OUs. For each OU, we provide the reference index $\mathrm{EI}_{\mathrm{OU}}^{r e f}$ in the first column, the average index $\mathrm{EI}_{\mathrm{OU}}^{a v g}$ in the second columns, and the standard deviation $S D$ in the last column.

\begin{tabular}{l|lll}
\hline OU & $\mathrm{EI}_{\mathrm{OU}}^{r e f}$ & $\mathrm{EI}_{\mathrm{OU}}^{a v g}$ & $\mathrm{SD}$ \\
\hline CTL & 0.94 & -0.81 & 0.35 \\
DO & 0.90 & -0.78 & 0.40 \\
EL & 0.88 & -0.78 & 0.42 \\
ITL & 0.79 & -0.69 & 0.48 \\
MML & 0.75 & -0.80 & 0.36 \\
MR & 0.25 & -0.86 & 0.35 \\
NCNR & 0.84 & -0.83 & 0.30 \\
PML & 0.65 & -0.85 & 0.31 \\
\hline
\end{tabular}



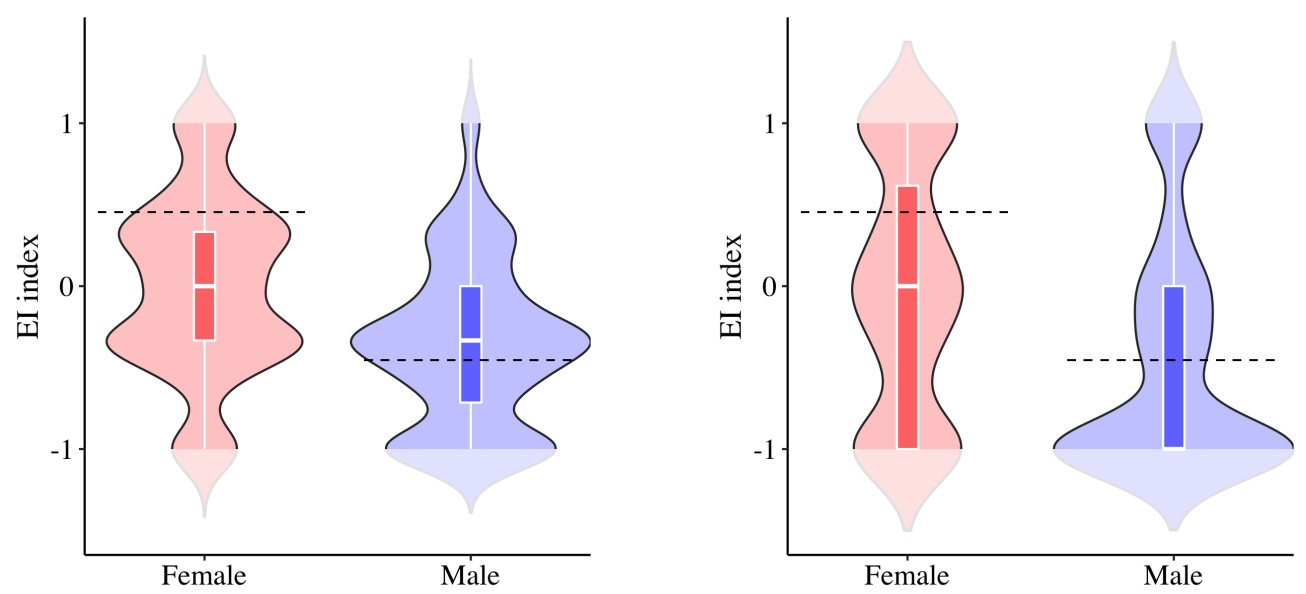

Fig. 19. The $\mathrm{EI}_{\alpha}$ index distribution between genders. The comparison of the $\mathrm{EI}_{\alpha}$ between genders for the work network (left) and for the advice network (right).

The $\mathrm{EI}_{\mathrm{OU}}^{\text {ref }}$ and $\mathrm{EI}_{\mathrm{OU}}^{a v g}$ values for each OU shown in Fig. 18 are presented in Table 2. The median $\mathrm{EI}_{\mathrm{OU}}^{\text {med }}=-1$ in the binary Lab vs. Non-Lab comparison as well as for all OUs presented in Fig. 18.

While we found no statistically significant differences in work networks composition between genders, the difference in network composition became significant for advice networks. Figure 19 shows a comparison of the $\mathrm{EI}_{\text {gender }}$ index distribution for females and males for both the work (left) and for advice networks. The gender distribution within the NIST Workforce is $72.7 \%$ males and $27.4 \%$ females, which means that we would expect to see about three times more males than females in a random ego network. This translates into $\mathrm{EI}_{\text {gender }}^{\text {ref }}=-0.45$ for males and $\mathrm{EI}_{\text {gender }}^{\text {ref }}=0.45$ for females. Interestingly, while for males the average $\mathrm{EI}_{\text {male }}^{\text {avg }}=-0.46(S D=0.7)$ for advice networks agrees with the reference, for females the average $\mathrm{EI}_{\text {female }}^{a v g}=-0.02(S D=0.75)$, For comparison, $\mathrm{EI}_{\text {male }}^{a v g}=-0.36$ $(S D=0.49)$ and $\mathrm{EI}_{\text {female }}^{a v g}=0(S D=0.54)$ for the work network. The median $\mathrm{EI}_{\text {female }}^{\text {med }}=0$ in both networks, while for males $\mathrm{EI}_{\text {male }}^{\text {med }}=-1$ in the advice network and $\mathrm{EI}_{\text {male }}^{\text {med }}=-0.33$ in the work network. This suggest that even though males are quite likely to report females in the work network, they exhibit strong homophilic preferences in their advice network. This observations is further confirmed by the fact that almost half of the males $(48.5 \%)$ reported fully homophillic networks. Moreover, as can be seen in the violin plot shown in the left plot in Fig. 19, there is a second peak in the work network, with $23.2 \%$ of males reporting network with $\mathrm{EI}_{\text {male }}=-1$, that is nearly a quarter of the male egos reported more homophilic networks than reference. At the same time only $2.4 \%$ of males reported heterophilic networks.

Females, on the other hand, tend to have much more balanced networks, with about $60 \%$ of females reporting work networks with $\mathrm{EI}_{\text {female }} \in(-0.35,0.35)$ and about $40 \%$ of females reporting advice networks with $\mathrm{EI}_{\text {female }}$ in this range. The violin plot for females work network, shown in the left plot in Fig. 19, exhibits a symmetric bimodal distribu- 


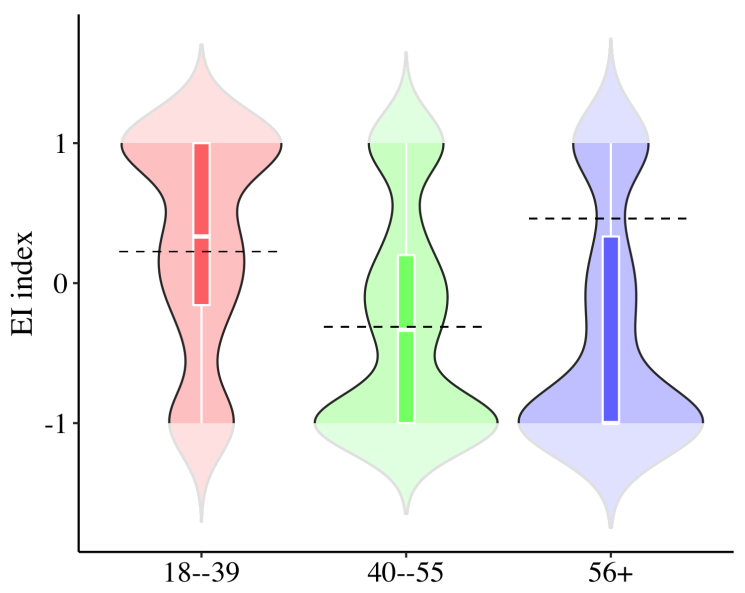

Fig. 20. The $\mathrm{EI}_{\alpha}$ index distribution the advice network between age groups. The comparison of the $\mathrm{EI}_{\alpha}$ between age groups for the advice network.

tion, with one peak aligning with NIST-Workforce-based reference $\left(\mathrm{EI}_{\text {female }} \in(0.3,0.6)\right.$ for $23 \%$ of female respondents) and the other peak corresponding to the opposite network composition $\left(\mathrm{EI}_{\text {female }} \in(-0.6,-0.3)\right.$ for $29.3 \%$ female egos $)$. The extreme cases of homophily and heterophily are rather rare and quite balanced, with $\mathrm{EI}_{\text {female }}=-1$ for $9.5 \%$ of females and $\mathrm{EI}_{\text {female }}=1$ for $8.7 \%$ of females. Interestingly, for the advice network, females were just as likely to report having either homophilic $\left(\mathrm{EI}_{\mathrm{female}}=-1\right.$ for $26.5 \%$ of females), heterophilic $\left(\mathrm{EI}_{\text {female }}=1\right.$ for $24.7 \%$ of females $)$, or perfectly mixed ego networks $\left(\mathrm{EI}_{\text {female }}=0\right.$ for $18.8 \%$ of females.

The age distribution of the NIST Workforce translates into $\mathrm{EI}_{\text {age }}^{r e f}=0.23$ for the $18-$ 39 group, $\mathrm{EI}_{\mathrm{age}}^{r e f}=0.32$ for the $40-55$ group, and $\mathrm{EI}_{\mathrm{age}}^{r e f}=0.46$ for the $56+$ group. The comparison of the $\mathrm{EI}_{\text {age }}$ index distribution between the different age groups is shown in Fig. 20. One can notice that the advice networks reported by the 56+ age group, with $\mathrm{EI}_{\text {age }}^{\text {avg }}=-0.34(S D=0.82)$ and $\mathrm{EI}_{\text {age }}^{\text {med }}=-1$, tend to be more homophilic that for the other two groups. The advice networks reported by the middle 40-55 age group, while still leaning towards homophily, are more balanced that in the older group $\left(\mathrm{EI}_{\text {age }}^{\text {avg }}=-0.33, S D=\right.$ $\left.0.77 ; \mathrm{EI}_{\mathrm{age}}^{\text {med }}=-0.33\right)$. Finally, the youngest group of egos (18-39) exhibits rather opposite trends. With $\mathrm{EI}_{\text {age }}^{\text {avg }}=0.3(S D=0.75)$ and $\mathrm{EI}_{\text {age }}^{\text {med }}=0.33$ respondents in the youngest group tend to report network leaning towards heterophily, that is preference for interactions with more senior employees.

Similarly to the work network, the $\mathrm{EI}_{\text {location }}$ index distribution between the three locations that correlates with the size of the sites (see the left plot in Fig. 21). Like before, the Maryland site seems to be the most homophilic $\left(\mathrm{EI}_{\mathrm{MD}}^{a v g}=-0.96, S D=0.2\right)$, followed rather closely by the Colorado site $\left(\mathrm{EI}_{\mathrm{CO}}^{\text {avg }}=-0.76, S D=0.53\right)$. The $\mathrm{EI}_{\text {location }}^{\text {med }}=-1$ for both sites. Likely do to its size, the "Other" location is the least homophilic, with $\mathrm{EI}_{\text {other }}^{\text {avg }}=-0.3$ $(S D=0.74)$ and $\mathrm{EI}_{\text {other }}^{\text {med }}=-0.38$.

The $\mathrm{EI}_{\mathrm{OU}}$ distribution for the advice network, shown in the right plot in Fig. 21, also 

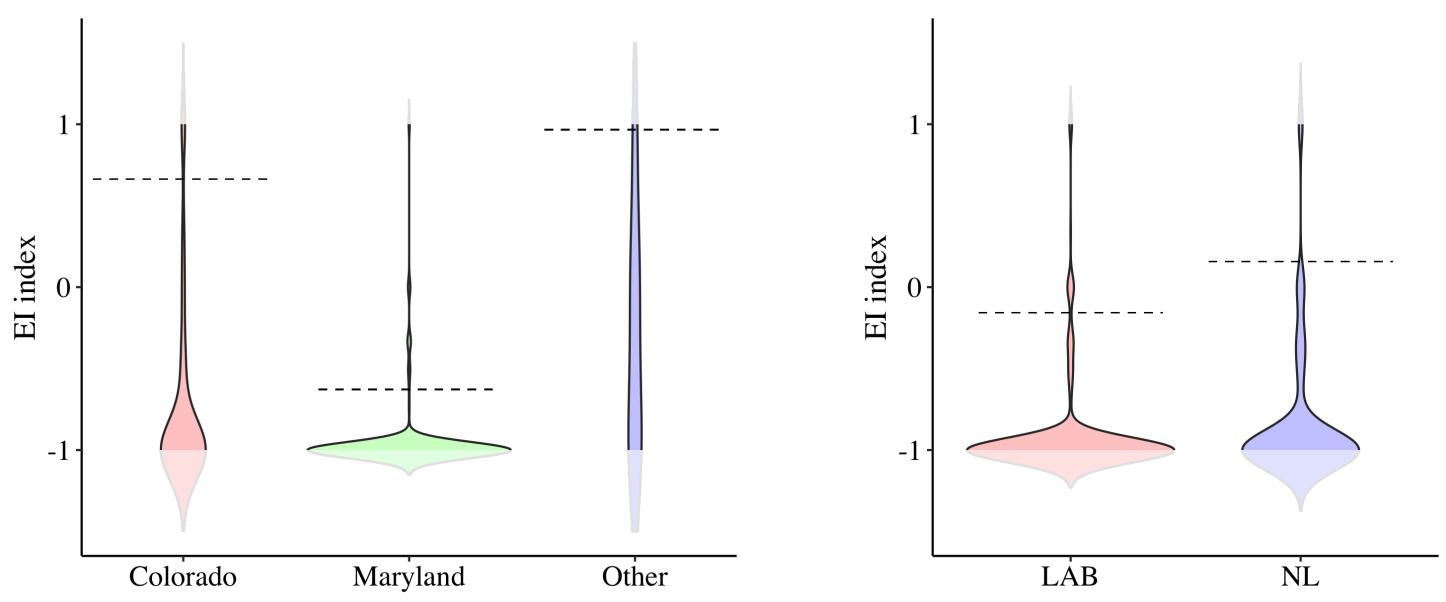

Fig. 21. The $\mathrm{EI}_{\alpha}$ index distribution in the advice network for location and $\mathrm{OU}$. The left plot shows comparison of the $\mathrm{EI}_{\alpha}$ based on egos locations and the right plot based on egos' binary (i.e., Labs vs. Non-Labs) OU affiliation.

closely resembles that for the work network. Both Labs and Non-Labs advice networks tend to be quite homophilic, with $\mathrm{EI}_{\mathrm{LAB}}^{a v g}=-0.92(S D=0.3)$ and $\mathrm{EI}_{\mathrm{NL}}^{a v g}=-0.84(S D=$ $0.41)$.

\section{Discussion}

NIST recognizes that diversity, equity, and inclusion (DEI) are key components in its mission of engaging innovation. In light of that recognition, NIST has traditionally allowed the organization of affinity groups and heritage events as well as provided cultural educational opportunities [46, 47]. This project is one of three data-driven studies recently launched to better understand the current state of DEI at NIST. Specifically, an ego network analysis (ENA) of federal employees was conducted to gauge the nature and composition of interactions at NIST.

Apart from catalyzing innovation, increasing DEI in an organizational setting is associated with a host of positive outcomes. However, while previous research suggests that diversity in teams can lead to more creative problem-solving [9] as well as other demonstrated benefits [10-14], other studies contend that diversity without inclusion can result in negative outcomes, such as perceived discrimination, less support from supervisors, and lower relationship quality [17]. An additional challenge lies in measuring inclusivity itself, which has been assessed in a variety of ways. For example, Sabharwal [48] approached the study of inclusivity by gauging organizational inclusive behaviors, measured by how individuals perceive that their leadership is committed to fostering inclusion, their ability to influence work group decisions, and the extent to which they are treated fairly. In turn, other researchers argue that there is a lack of consistency regarding which specific behaviors and actions actually exemplify inclusion [49]. 
By developing and implementing an innovative method for gauging organizational inclusivity, this study helps to fill in the existing gap in the literature as well as it contributes to recent government-mandated efforts towards advancing our understanding of and commitment towards diversity, equity, and inclusion. In fact, a recent Executive Order on Advancing Racial Equity and Support for Underserved Communities Through the Federal Government explicitly calls for identifying methods to assess equity in the federal government [50]. As part of our study, we employed a social network analysis approach to measure inclusivity. Specifically, we assessed ego networks that stem from different interactions that take place as work is conducted at NIST.

The literature in this area suggests that, within an organization, there are different ways and purposes for which its members interact with one another. This study focused on two types of interactions. The first type of interaction is that which pertains to achieving workrelated goals at NIST, it can be understood as the "work network." In the context of this project, a work network is comprised of what previous researchers call instrumental or workflow ties-the relationships that develop between two individuals in an organizational setting from the performance of work roles [51]. Research has shown that work or instrumental ties can play a role in how people feel about their job [52], overall performance [53], as well as managerial performance and innovation [54].

In turn, the second type of interaction explored in this study involves seeking advice about career-related decisions at NIST, the "advice network". In previous research, advice networks in an organization have been attributed to the transmission of information between its members through informal ties and interactions [55]. The importance of this particular type of network stems from the belief that informal interactions may play a crucial role in obtaining influence within an organization, which in turn then affects career success and upward mobility [34]. More recent work in this area highlights that embeddedness in advice networks can also have significant implications for job performance [56], embracing existing as well as new organizational values [57], and job involvement [58].

One of the main questions broached by this study was whether there were any differences between work and advice networks, specifically regarding network size and composition. In the context of this study, network size refers to the number of people (i.e., alters) that respondents listed when prompted to describe their work or advice-seeking interactions. Previous work in this area suggests that how a network is defined ultimately determines its size [59]. Thus, we expected to see some difference in size between the two types of networks considered in this study. Especially that the two networks had different constraints imposed in the size: the study design required participants to list as few as three and as most as nine alters for work interactions, while the advice-seeking interactions had no lower bound. The minimum requirement for the work interactions prompt stems from NIST-specific work routines that expect a given employee to interact, at minimum, with three individuals: their direct supervisor (e.g. group leader), their supervisor's supervisor (e.g. division chief), and the administrative office assistant to conduct their work. In turn, limiting the number of alters that could be listed to nine was a study design strategy intended to reduce respondent fatigue-a methodological best practice highlighted in social 
science research to avoid the deterioration of survey data quality that occurs with longer survey lengths [60]. In addition, similar survey prompt constraints have been implemented in previous social network research [34].

Another potential explanation for the differences in network size is that, when seeking advice, people must carefully consider the costs and benefits of those interactions. Indeed, previous studies in advice seeking contend that this type of information-seeking behavior involves costs for the person being asked for advice and benefits for the person seeking advice - and because of this trade off, people must carefully consider from whom they seek advice [61, 62]. In addition, while research suggest advice seekers are perceived as more competent when they ask others for advice [63], intuitively people may be reticent in seeking advice from others out of fear of appearing incompetent. Interestingly, we also find that respondents in the 56+ age groups are significantly more likely to report empty advice networks than respondents in the 18-39 age groups, which suggests that egos in the $56+$ age groups may have advice networks outside NIST.

An additional question broached by this study sought to explore whether (and if so, how) NIST work and advice networks differ in composition. When considering work interactions, two main findings can be identified. First, participants were more likely to list alters affiliated with Lab OUs rather than Non-Lab OUs. Further, the Lab-to-Non-Lab $(\mathrm{L} / \mathrm{NL})$ ratio was larger for male participants $\left(\mathrm{L}_{\mathrm{NL}} \mathrm{Lale}_{\text {e }}=2.7, \mathrm{~L} / \mathrm{NL}_{\text {female }}=1.4\right)$, those that work in a lab organizational unit $\left(\mathrm{L} / \mathrm{NL}_{\mathrm{lab}}=12.4, \mathrm{~L} / \mathrm{NL}_{\text {non-lab }}=0.1\right)$, and respondents that indicated that they do not work in Maryland $\left(\mathrm{L} / \mathrm{NL}_{\text {non-MD }}=4.3, \mathrm{~L} / \mathrm{NL}_{\mathrm{MD}}=1.7\right)$. We also found that participants with supervisory status were more likely to list alters that were younger rather than older $\left(\mathrm{Y} / \mathrm{O}_{\text {sup }}=2.1\right)$ compared to participants that did not identify themselves as supervisors $\left(\mathrm{Y} / \mathrm{O}_{\text {non-sup }}=0.9\right)$. The latter might be reflective of the fact that supervisors have to interact with their direct reports (often younger than themselves) to achieve the work goals of the year. The report-like nature of these interactions is further supported by the fact that the more frequent interactions with younger alters reported by supervisors do not translate onto advice networks. Indeed, we do not find any significant correlations in advice networks between the respondents age and the alters' supervisory status. We do, however, find a significant correlation between the egos and alters age, with respondents in all age groups showing preference for advice-related interactions with more experienced colleagues (that is colleagues in the 40+ age groups). Since age fairly directly translates onto the total years in the workforce, this suggests that it is the total years of professional career rather than status achieved at NIST that the respondents value.

According to the NIST Workforce data, these work interaction findings align closely with what could be expected given NIST's organizational makeup. Regarding organizational units, workforce data illustrates that $64 \%$ percent of NIST federal employees work in lab organizational units. The percent of members of the entire NIST Workforce (including federal employees and associates) with Lab OU affiliation is also larger (58\%) compared to those with Non-Lab OU affiliation. Similarly, most of the survey respondents (69\%) indicated that they work in Lab OUs. Complementary to this data, our study confirmed that people employed in any of the Lab OUs tend to interact more with colleagues 
affiliated with the same organizational unit. When alters are affiliated with an OU different from their own, there is a preference for OUs of the type that the ego is in. This suggests the potential presence of organizational silos within NIST. Importantly, organizational silos are generally understood as barriers for communication and information flow [64].

Also two main findings emerge when considering advice interactions. First - and similar to what was seen with work interactions - participants showed strong preference to seek out advice from people that work in the same OU. Further, the L/NL ratio was larger for male participants and respondents that indicated that they do not work in Maryland. These findings underscore the similarity between work and advice-seeking interactions. This suggests that NIST federal employees not only work closely together with other peers in the same OU, but that they are seeking career-related advice from the same place. It also implies the prevalence of organizational silo structures in advice networks.

The second advice network finding concerns gender. While male participants were more likely to list male rather than female peers as part of their advice-seeking interactions $\left(\mathrm{M} / \mathrm{F}_{\text {male }}=1.9\right)$, for females $\mathrm{M} / \mathrm{F}_{\text {female }}=1$, indicating no gender-based preferences. This is particularly interesting considering the demographics of the NIST Workforce data, which shows that nearly three quarters of all staff are male. An even more interesting dynamic emerges when considering gender through the third network aspect of this study: homophily. More on that later in this section.

Generally, homophily is understood as the principle that contends that people tend to interact more with similar rather than dissimilar folks [65]. In the context of this study, homophily refers to the extent that an ego and its alters-that is respondents and the colleagues they list-share similar characteristics in regards to gender, age, location, organizational units, or supervisory status. Because assessing tenure of someone else is rather difficult and assigning a race falls under the umbrella of racial profiling [66], our survey did not ask participants to provide these attributes for the alters.

When focusing on work interactions, it was found that participants from all sites tend to interact the most with other folks based in the same physical location. Similar findings also emerged for advice networks. This suggests that respondents prefer to both work with and seek advice from colleagues who are in close physical proximity. An additional advice network homophily finding emerged. Participants in the younger group (from 18 to 39 years old) tend to seek advice from older colleagues. In contrast, participants in the 40-55 and 56+ age groups show preference for interacting with alters in the same age group, respectively.

When focusing on whom female participants listed as part of their advice network, three prevalent trends appear: female-dominated, male-dominated, and relatively equal parts male and female advice networks. This finding is telling when put in contrast with what was seen-or rather, not seen-for work-related interactions, primarily because while Federal Employees at NIST may not have full authority in choosing who they work with, seeking advice requires taking initiative since it is not a work-mandated function [61]. Interestingly, previous research suggest that the establishment of "networks of choice" (equivalent to advice networks in this study) is the most important factor for increasing 
retention, especially for minorities [67]. Recognizing how female employees prefer to interact when seeking advice is essential for informing new and ongoing efforts that intend to make NIST a more welcoming environment for females.

Another area of interest explored in this project was whether race played a role in the composition of participants' work and advice-seeking networks. To that end, participants were asked to disclose which ethnic/racial category they identified with; options included either minority (i.e., American Indian, Asian, Black, Hispanic, Native Hawaiian, Other) or non-minority (White). The reason we opted to measure participants' race in a dichotomous way (i.e., minority/non-minority) was to protect the respondents anonymity as the minority population in the NIST Federal Workforce is relatively small. While the decision was made to protect the respondents anonymity, minorities are not a monolithic whole. For instance, Asians' experiences are not the same as Blacks' experiences, and neither is the same as the experiences of Hispanics. Results of the analysis by race were somewhat similar to the NIST Federal Workforce data: most participants identified as non-minority; however, the fraction of respondents who self-identified as minority was smaller than expected based on NIST Federal Workforce data. Analyses based on race did not yield statistically significant differences between non-minority and minority participants regarding network composition. However, it is possible that combining all the minority racial groups into one might have resulted in averaging and neutralizing possibly extreme reports.

Taken together, these study findings describe the way in which NIST federal employees interact with other colleagues at NIST-and more generally, they point to certain organizational trends concerning inclusivity. Despite putting constraints on work and advice networks, the network sizes found are within the range of what would be expected [68]. Second, regarding network composition, our findings suggest the presence of organizational silos at NIST. It could be argued that both the current organizational structure as well as the specialized work that is conducted at NIST lend themselves to this kind of network dynamic. However, research in this area has shown that the spread of complex ideas and innovation depend both on highly connected networks as well as wide bridges to other clusters [64]. It stands to reason, then, that fostering more interconnections between different groups at NIST could facilitate knowledge transfer and drive innovation.

Finally, the findings also shed light into who is and who is not listed as part of their advice networks. Males, who comprise nearly three fourths of all federal employees at NIST, do not tend to seek advice from females. These trends are not unique to NIST-there is a whole body of work that has shown that females are often not sought for advice, and that this lack of inclusion has detrimental effects on the career prospects of females [34, 69]. Interestingly, these facts and the dynamics that they precipitate do not impede females from seeking other females as part of their advice-seeking interactions. This too aligns closely with existing research, which has shown that folks tend to gravitate towards folks of a similar gender when seeking career advice [30]. These tendencies underscore the importance of ensuring diversity in supervisory positions, especially considering the studies that suggest that demographic similarities and differences between supervisors and their subordinates can affect performance rating as well [70]. 
Limitations: Although this study employed an innovative approach to measure inclusivity at NIST, there are several limitations. First, data was collected during the COVID-19 pandemic, a moment in time characterized by atypical work-from-home modalities that may have impacted the interactions we sought to measure, particularly those pertaining to advice-seeking. Another limitation is the already mentioned dichotomized race. Critical nuance is lost when attempting to gauge inclusivity in an organization or the lack thereof in this way. Future work should consider shifting the granularity from OUs to race.

\section{Conclusions}

Exploring methods to measure inclusion in the workplace is an important aspect of advancing inclusivity practices at NIST. This work demonstrates how analysis of anonymous ego-centric social networks can be leveraged to explore various types of interaction networks at NIST. The insights learned from this study shed light on the nature of inclusion in work and advice interactions. The former pertains to interactions related to "getting work done", and the relationships mapped as part of those interactions comprise what we call the "work network." The latter, on the other hand, focuses on informal advice-seeking interactions, and the relationships mapped as part of those interactions comprise what we call the "advice network." The results of this study represent a snapshot of the work and advice interaction patterns of the NIST Federal Employees that participated in the survey. A summary of the conclusions is presented below.

The results shown herein demonstrate that the NIST Interactions Survey successfully maps employee ego networks in two distinct settings: work and advice. Data analysis confirms that the formal (work) and informal (advice) networks provide important insights into the patterns of interactions at NIST that are inaccessible through more traditional surveys. One of the differences that we found suggests that network composition is contingent on different ego characteristics. For instance, in the case of work networks, OU affiliation for the most part shapes network composition patterns, whereas in the case of advice networks, gender and age plays an equally important role. Interestingly, these gender- and age-based differences are not observed in the work networks. This finding suggests that work networks could be understood as "networks of convenience", where the employees simply work together on projects that are of interest to NIST. The advice networks, on the other hand, are quite different between the various demographic groups, suggesting that more preferential decisions take place when forming them. As such, these can be thought of as "networks of choice".

Our analyses confirms the existence of organizational silos in work and advice networks. In particular, we observe that work networks exhibit dependence on the respondents' OU where employees show preference for interacting with colleagues affiliated with the same organizational unit or, if not the same OU, the same type of OU (i.e. Lab or Non-Lab). Interestingly, advice networks display strikingly similar dependence on the respondents OU. Such strong similarity between work and advice-seeking interactions under-

score the pervasive nature of these silo structures, which potentially can represent barriers 
for communication and information flow. The spread of complex ideas and innovation depend both on highly connected networks as well as wide bridges to other clusters.

Results from this work also reveal clear differences in the characteristics of advice ego networks between male and female employees. Interestingly, we find gender-based differences in advice networks that are absent in the work network, which point to preferential decisions being made when forming advice networks. Male employees reported strongly male-dominated advice networks whereas female employees revealed three prevalent trends: female-dominated, male-dominated, and relatively equal parts male and female advice networks. Given that nearly three quarters of NIST staff population are male, establishing gender-neutral and female-dominated advice networks may be a very challenging task for female employees. Acknowledging the intrinsic differences in the way males and females interact when seeking advice creates a unique opportunity to be more intentional in nurturing informal networks. This is particularly important in the light of previous research arguing that the establishment of network of choice (e.g. advice networks in this study) is the most important factor for increasing retention. To encourage more females to seek employment at NIST (or more female Associates to consider staying at NIST) we need to create an environment where females (and other underrepresented minorities) have the opportunity to built advice networks they need.

We find a significant correlation between the age of egos and alters. Specifically, respondents in the 18 to 39 age group showed a preference for seeking advice from older colleagues. Since age is a fair proxy for total years in the workforce, this finding suggests that work experience may be a driving factor when seeking sources of career-related advice. This stands in contrast with supervisory status, for which we did not find a statistically significant correlation. Taken together, these findings outline that while NIST employees are seeking advice from more experienced colleagues-that does not necessarily suggest that they are turning to supervisors for the career-related information they need.

Finally, our study finds no significant differences between the networks of minority and non-minority employees for either work or advice networks. Both minority and nonminority participants showed similar work and advice networks, which reflects similarities in the interaction patterns when the racial category is grouped in this binary way (e.g., minority vs non-minority). While we would have liked to study the interactions patterns among employees from different minority groups in a more granular way (i.e., American Indian, Asian, Black, Hispanic, Native Hawaiian, Other), we were not able to do so to preserve anonymity. Given the small percent of employees representing some of these minority groups at NIST, the specificity of the minority group along with the OU affiliation could in some cases make them identifiable.

We hope this study will inform ongoing and future NIST's inclusivity initiatives and recommend some strategies in the next section associated with the findings of this work. We note that our study also opens the pathway to visualizing interaction patterns among staff according to attributes that extend beyond those used in this study. 


\section{Recommendations}

The extent to which a workplace is perceived as inclusive is contingent on employee access to information and resources. In an organizational setting like NIST, information flow can take place through formal and informal interactions between its members. Our study demonstrates that social network analysis can be leveraged to capture and quantify these interaction patterns. Key findings of this work include the need to bridge communication barriers between the Organizational Units, known as Labs, and the rest of the Non-Labs Organizational Units, prevalent in both the work and advice networks. In addition, there is a need to promote and nurture informal connections among female colleagues, particularly given our current male-dominated workforce. Finally, mapping advice networks in a post-covid time and capturing differences in the personal networks among different minority groups might provide valuable information. Based on these findings, we provide the following recommendations.

Create opportunities for employees from Lab and Non-Lab organizational units to develop more inter-connected work networks. Our study confirmed the presence of silos between Lab and the Non-Lab OUs in work networks, which creates barriers in the communication flow. To bridge these silos, we recommend that NIST establishes a formal Leadership Rotational Program (LRP) for employees to pursue project-based assignments for six to twelve months at a time across different OUs. Because we observed consistent siloed effect between Lab and Non-Lab OUs, the program would benefit from including both types of OUs. An LRP managed at a central level helps with defining the program's scope, success metrics, and a candidate application and selection process that benefits both Lab and Non-Lab OUs. From the employee's perspective, LRPs provides a unique opportunity for leadership development, great exposure to alternative career paths, and a breadth of organizational knowledge. Because LRPs force employees to constantly navigate change, the program's success is tied to the support provided by the host OUs as the "temporary team member" moves through the various stages of the program.

Apart from an LRP, we also recommend that NIST creates a central hub to support existing and facilitate the creation of new Communities of Practice (CoPs). CoPs are organized groups of employees who are practitioners of a well-defined job function in the organization and share a desire to get better at what they do by exchanging tips and best practices with peers in other parts of the organization. As an example, job functions that can benefit from CoPs are group leaders, office managers, and program managers. CoPs offer members the opportunity to connect with other members, thereby facilitating the advancement of employee collective knowledge in an important field or domain. CoPs are known to accelerate professional development, connect silos, and lead to happier and better motivated employees. These collaborations rooted on a purpose outside of employees' standalone jobs can afford many benefits including granting autonomy, feelings of support, and a sense of stewardship as well as belonging. Further, CoPs also enable opportunities for rapid problem-solving, benefiting the entire organization as well. A key ingredient for successful CoPs is to provide guidance and support necessary to create a formal leadership 
team for each CoP. Without a CoP leadership team, spontaneous connections between individuals in a given CoP would emerge very slowly or not at all, and existing connections could start to fade away until eventually the community becomes inactive. The benefits of supporting the creation of CoPs at a central level extend beyond improving communication among employees from different silos and can have long lasting impact.

Promote informal connections between silos by providing organizational, financial, and executive support for existing Employee Resources Groups (ERGs). Our study confirmed that siloed communication between Labs and Non-Labs organizational units extends to advice networks. To bridge this connection gap, we recommend that NIST takes advantage of an already existing resource: employee resources groups (ERGs), more commonly known at NIST as affinity groups. ERGs are networks of employees who, within NIST, are united based on shared common experiences, characteristics, or goals. ERGs offer members opportunities to socialize and organize discussions and events to raise awareness of issues that are relevant to the membership, thereby facilitating the creation of informal interactions. Because ERGs connect employees regardless of location or rank in the organization, they are perfect hubs to nurture interactions centered around a meaningful purpose among employees across different OUs. While NIST has numerous ERGs, establishing a directive that formalizes the requirements, roles, and responsibilities for all NIST employee organizations would make these groups stronger. Providing the means for ERGs to have formal bylaws as well as financial and executive-level support gives ERGs a better chance of staying active and be more impactful for employees. As in the case for CoPs, establishing and recognizing the value of supporting a formal ERG leadership team is essential to ensure the momentum and energy continues steadily with membership united to achieve the intended goals and purpose of the ERG community for a long time. The benefits of connecting employees across silos through informal networks are long lasting. To maximize their impact, sharing best practices among the leadership teams from across all ERGs would be beneficial.

Establish a Women Mentorship Circle Program that fosters informal connections among female employees. Our study found that there is a significant population of female employees that prefers to seek advice from networks that are composed of $50 \%$ or more females. Achieving such high percent of females in advice networks can be challenging at NIST given that almost three quarters of the current workforce are male. To decrease barriers that some female employees may be facing when trying to connect with other female colleagues, we recommend that NIST establishes a formal program that nurtures social interactions among existing female employees. A key element for the success of this kind of program is to ensure that participation accomplishes a goal that would otherwise be unattainable at an individual level. With that in mind, fostering female-only relationships centered around mentoring would be a great mechanism to get us started. To achieve that, we recommend establishing a Women Mentorship Circle Program. A mentorship circle is a group of eight to twelve colleagues (mentees) who for a period of time (e.g., eight months) participate in monthly meetings hosted by a more experienced colleague (i.e., Circle mentor) with the purpose of sharing ideas, best practices, and challenges in 
a safe environment. A formal Mentorship Circle Program would recruit candidates (both mentor and mentees) and provide participants with the opportunity to receive support and share lessons learned. Since our analysis shows that respondents do not consider the supervisory status to be important when seeking advice, the pool of potential female mentors in the program can be substantially increased by incentivizing participation from experienced non-supervisor females. An essential aspect to consider for the program to be successful at recruiting female Circle mentors is to ensure that participating in the Mentorship Circle Program is considered part of her career progression.

Consider mapping the advice ego networks of employees at another point in time. Our study validated that work and advice networks provide important insights into the patterns of interactions at NIST. The value of the methodology developed in this study could extend to adding key insights over time if the NIST Interactions Survey were to be launched again. For example, the data for this study was collected during the COVID19 pandemic, a moment in time characterized by atypical work-from-home modalities that may have impacted the perception of access to advice-seeking connections. We recommend that NIST considers launching a shorter version of the NIST Interactions Survey in a postpandemic future. In addition to modifying the length of the survey, it could also be centered around the advice network and the attributes for which differences are to be expected given the findings in this study. Another modification we recommend relates to capturing the race category in a different way, more details are stated below.

Focus on racial and ethnic nuance when assessing employee ego networks. Our study found no discernible differences in the work and advice networks between minority and non-minority employees. Should NIST decide to run another version of the NIST Interactions Survey, we recommend investigating whether differences exist in the advice networks among minority subgroups (i.e., American Indian, Asian, Black, Hispanic, Native Hawaiian, Other). To achieve this goal, we recommend two additional changes apart from focusing on the advice network. In order to continue preserving the privacy of participants, we recommend that the increase in the granularity of the racial information be compensated by a reduction in the granularity of OU affiliation to simply stating whether the participant is from a Lab or Non-Lab OU.

\section{Acknowledgments}

We would like to acknowledge everyone who made this study possible, starting with Dr. James Olthoff, the Associate Director of Laboratory Programs (ADLP) Performing Duties of the NIST Director, for providing the financial support to perform this study. We also want to recognize the Office of Human Resources Management (OHRM) and the Steering Group for Equity in Career Advancement (SGECA) for jointly sponsoring this opportunity to study aspects of equity, diversity, and inclusion in the NIST community. We want to thank the current Acting ADLP, Dr. Eric Lin, for providing key guidance towards the end of the project. We would also like to acknowledge Teresa Sorcek, Teresa Whiteside, and Jasmine Ventura of OHRM for pulling and consolidating the NIST Federal Workforce 
data for this work and Patrick Gleichmann of the NIST Associates Information System for extracting the NIST Associates data used in this study. A special thanks to Zachary Trautt who (after approval from the OISM Assessment and Authorization team), wrote, tested, and deployed a privacy-preserving script that provided a personalized survey link for every email recipient. Also, a big thanks to Amanda Koepke, Jared Ragland, and Zachary Trautt who, in the early stage of the project, served in a consulting role and provided general guidance on broader web application concerns associated with developing data collection tools. We would also like to thank Assistant Professor Remy Dou from the Department of Teaching and Learning at Florida International University and Associate Professor Eric Brewe from the Department of Physics at Drexel University for providing detailed feedback on the work and advice network questions in the NIST Interactions Survey. Lastly, we would like to thank all the survey respondents who kindly provided input for this study as well as the following colleagues at NIST who provided constructive feedback on earlier versions of this report: Heather Evans, David LaVan, Edwin Chan, and Judith Terrill. 


\section{References}

[1] NIST Mission, Vision, Core Competencies, and Core Values. https://www.nist.gov/ about-nist/our-organization/mission-vision-values.

[2] National Institute of Standards and Technology (2019) Inclusivity Summit for Managers and Supervisors at NIST.

[3] Espinal L, Evans H, Lawson J (2019) Summary of Findings from the Inaugural Equity Café held in December 2018 at NIST Gaithersburg. NIST Equity Café Rep.

[4] Espinal L, Evans H, Lawson J (2019) Summary of Findings from the Equity Café held in March 2019 at NIST Boulder. NIST Equity Café Rep.

[5] Wilkinson R (2020) A Long Way to Go: Addressing Equity and Inclusion at NIST. NIST Connect. (September)

[6] Boss A (2020) Progress on the Equity and Inclusivity Initiatives. NIST Connect. (January)

[7] Executive Order 13583 (2011) Establishing a Coordinated Governmentwide Initiative to Promote Diversity and Inclusion in the Federal Workforce. https://obamawhitehouse.archives.gov/the-press-office/2011/08/18/executive-order13583-establishing-coordinated-government-wide-initiativ

[8] Mannix E, Neale MA (2005) What Differences Make a Difference?: The Promise and Reality of Diverse Teams in Organizations. Psychol. Sci. Public Interes. 6(2):31-55. https://doi.org/10.1111/j.1529-1006.2005.00022.x

[9] Hoffman LR (1959) Homogeneity of Member Personality and its Effect on Group Problem-Solving. J. Abnorm. Soc. Psychol. 58(1):27-32. https://doi.org/10.1037/ h0043499

[10] Campbell LG, Mehtani S, Dozier ME, Rinehart J (2013) Gender-Heterogeneous Working Groups Produce Higher Quality Science. PLoS One 8(10):1-6. https://doi. org/10.1371/journal.pone.0079147

[11] Freeman RB, Huang W (2014) Collaborating With People Like Me: Ethnic Coauthorship within the US. NBER Working Paper No. 19905, JEL No. J01,J1,J15 http://www.nber.org/papers/w19905

[12] Torchia M, Calabrò A, Gabaldon P, Kanadli SB (2018) Women Directors Contribution to Organizational Innovation: A Behavioral Approach. Scand. J. Manag. 34(2):215224. https://doi.org/10.1016/j.scaman.2018.02.001

[13] Bear J, Woolley AW (2011) The Role of Gender in Team Collaboration and Performance. Interdiscip. Sci. Rev. 36(2):146-153. DOI:10.1179/ $030801811 X 13013181961473$

[14] Gomez LE, Bernet P (2019) Diversity Improves Performance and Outcomes. J. Natl. Med. Assoc. 111(4):383-392. doi:10.1016/j.jnma.2019.01.006

[15] Peel L, Delvenne JC, Lambiotte R (2018) Multiscale Mixing Patterns in Networks. Proc. Natl. Acad. Sci. 115(16):4057-4062. https://doi.org/10.1073/pnas.1713019115

[16] Perez A (2018) Bridging the Inclusion Gap: Creating Transformation in the Workplace. Capstone Research Report Submitted in Partial Fulfillment of the Requirements 
for the Master of Nonprofit Administration Degree in the School of Management (University of San Francisco). https://cpb-us-w2.wpmucdn.com/usfblogs.usfca.edu/ dist/9/244/files/2018/09/perezalyssa_6183931_64785637_Alyssa-Perez_CapstoneReport-15a1a7i.pdf

[17] Riordan CM (2014) Diversity is Useless Without Inclusivity. Harv. Bus. Rev. https: //hbr.org/2014/06/diversity-is-useless-without-inclusivity

[18] McGrath JE, Berdahl JL, Arrow H (1995) Traits, Expectations, Culture, and Clout: The Dynamics of Diversity in Work Groups. In Jackson SE, Ruderman MN (Eds.), Diversity in Work Teams: Research Paradigms for a Changing Workplace (p. 17-45). American Psychological Association. doi:https://doi.org/10.1037/10189-001.

[19] Roberson QM (2006) Disentangling the Meanings of Diversity and Inclusion in Organizations. Gr. Organ. Manag. 31(2):212-236. https://doi.org/10.1177/ 1059601104273064

[20] Jones G, Bernardita CC, Wright J (2020) Cultural Diversity Drives Innovation: Empowering Teams for Success. Int. J. Innov. Sci. 12(3):323-343. https://doi.org/10. 1108/IJIS-04-2020-0042

[21] Mor-Barak M, Cherin DA (1998) A Tool to Expand Organizational Understanding of Workforce Diversity. Adm. Soc. Work 22:47-64. https://doi.org/10.1300/J147v22n01_ 04

[22] Østergaard CR, Timmermans B, Kristinsson K (2011) Does a Different View Create Something New? The Effect of Employee Diversity on Innovation. Research Policy 40(3):500-509. https://doi.org/10.1016/j.respol.2010.11.004

[23] Parrotta P, Pozzoli D, Pytlikova, M (2014) The Nexus Between Labor Diversity and Firm's Innovation. Journal of Population Economics 27(2):303-364. https://doi.org/ 10.1007/s00148-013-0491-7

[24] Nathan M, Lee N (2013) Cultural Diversity, Innovation, and Entrepreneurship: Firmlevel Evidence from London. Economic Geography 89(4):367-394. https://doi.org/ 10.1111/ecge. 12016

[25] Crossley N, Bellotti E, Edwards G, Everett MG, Koskinen J, Tranmer M (2015) Social Network Analysis for Ego-Nets. (SAGE Publications Ltd).

[26] Fisher D (2005) Using Egocentric Networks to Understand Communication. IEEE Internet Comput. 9(5):20-28. doi:10.1109/MIC.2005.114

[27] Perry BL, Pescosolido BA, Borgatti SP (2018) Egocentric Network Analysis: Foundations, Methods, and Models. (Cambridge University Press.). https://doi.org/10. 1017/9781316443255

[28] Hansen DL, Shneiderman B, Smith MA (2011) Analyzing Social Media Networks with NodeXL: Insights from a Connected World. Morgan Kaufmann. https://doi.org/ 10.1016/C2009-0-64028-9

[29] Everett M, Borgatti SP (2005) Ego Network Betweenness. Soc. Networks 27(1):3138. https://doi.org/10.1016/j.socnet.2004.11.007

[30] Aley MR, Levine KJ (2020) From Whom Do Young Adults Actively Seek Career Information? An Ego-Network Analysis of Vocational Anticipatory Socialization. 
Commun. Stud. 71(2):351-367. https://doi.org/10.1080/10510974.2020.1735465

[31] Arnaboldi V, Conti M, Passarella A, Pezzoni F (2012) Analysis of Ego Network Structure in Online Social Networks. Proc. - 2012 International Conference on Privacy, Security, Risk and Trust and 2012 International Conference on Social Computing, pp. 31-40. doi:10.1109/SocialCom-PASSAT.2012.41

[32] Borgatti SP, Mehra A, Brass DJ, Labianca G (2009) Network Analysis in the Social Sciences. Science 323 (5916):892-895 DOI:10.1126/science.1165821

[33] Nagel M, Stark M, Satoh K, Schmitt M, Kaip E (2019) Diversity in Collaboration: Networks in Urban Climate Change Governance. Urban Clim. 29:100502. https:// doi.org/10.1016/j.uclim.2019.100502

[34] Brass DJ (1985) Men's and Women's Networks: a Study of Interaction Patterns and Influence in an Organization. Acad. Manag. J. 28(2):327-343. www.jstor.org/stable/ 256204

[35] Krivitsky PN, Morris M (2017) Inference for Social Network Models from Egocentrically Sampled Data, with Application to Understanding Persistent Racial Disparities in HIV Prevalence in the U.S. Ann. Appl. Stat. 11(1):427-455. DOI:10.1214/16AOAS1010

[36] Morrison EW (2002) Newcomers' Relationships: The Role of Social Network Ties during Socialization. Acad. Manag. 45(6):1149-1160. https://www.jstor.org/stable/ 3069430

[37] Yan Y, Guan J (2018) Social Capital, Exploitative and Exploratory Innovations: The Mediating Roles of Ego-Network Dynamics. Technol. Forecast. Soc. Change 126:244-258. https://doi.org/10.1016/j.techfore.2017.09.004

[38] Yang R, Bai Y, Qin Z, Yu T (2014) EgoNet: Identification of Human Disease EgoNetwork Modules. BMC Genomics 15:314. https://doi.org/10.1186/1471-2164-15314

[39] The information sheet describing the NIST Interactions Survey survey can be found in the NIST internal website at the following link. https:/inet.nist.gov/system/files/ documents/2020/10/28/information.pdf

[40] Krackhardt D, Stern RN (1988) Informal Networks and Organizational Crises: An Experimental Simulation. Soc. Psychol. Q. 51(2):123-140. https://www.jstor.org/ stable/2786835

[41] Norušis MJ (2012) IBM SPSS Statistics 19 Statistical Procedures Companion. vol. 496 (Prentice Hall).

[42] R Core Team. (2015) R: A Language and Environment for Statistical Computing. in R Foundation for Statistical Computing.

[43] Wickham H, François R, Henry L, Müller K (2020). dplyr: A Grammar of Data Manipulation. R package version 1.0.2. https://CRAN.R-project.org/package=dplyr

[44] Krenz T, Krivitsky PN, Vacca R, Bojanowski M, Herz A (2020). egor: Import and Analyse Ego- Centered Network Data. R package version 0.20.06. https://CRAN.Rproject.org/package $=$ egor

[45] Wickham H (2016) ggplot2: Elegant Graphics for Data Analysis. Springer-Verlag, 
New York, 2016.

[46] NIST. (2019, September 24). Diversity, Inclusion and Equity. NIST. https://www.nist. gov/diversity-inclusion-and-equity

[47] Voluntary Employee Organizations \& Employee Resource Groups at NIST: PML APS-IDEA (Inclusion, Diversity, and Equity Alliance) TEAM, EL Diversity, Inclusion \& Belonging (DIB) Council, Employee Resource Council, Association of NIST Asian-Pacific Americans (ANAPA), NIST Association for Black Staff (NABS), Association at NIST of Hispanic Americans (ANHA), NIST \& NOAA Pride Group, Veterans Affinity Group, Women in STEM, Postdoctoral and Early-career Association of Researchers (PEAR), The Parents Network (ParentsNet), Toastmasters Club, DISTEM FORUM, Standards Alumni Association, Take Our Daughters and Sons To Work Day (TODSTWD), NIST Chapter of Sigma Xi, Adventures in Science, Boulder Association of Women in Science (BAWS), Guest Researcher Association, Book Club, Caregiver Group, Prayer Group, Viet-NIST, Standard Stitchers: Fiber Crafting Hour, Standards Employees Benefit Association known as "SEBA", which includes the following Sports Teams \& Recreational Clubs: Bowling, Garden Club, NIST Golf Association, Ski Club, Soccer, Softball, Tennis, Fitness Center, Exercise Classes, Yoga/Pilates).

[48] Sabharwal M (2014). Is Diversity Management Sufficient? Organizational Inclusion to Further Performance. Public Personnel Management 43(2):197-217. https://doi. org/10.1177/0091026014522202

[49] Winters MF (2014). From Diversity to Inclusion: An Inclusion Equation. In Diversity at Work: The Practice of Inclusion (eds Ferdman BM and Deane BR) (pp. 205-228). Jossey-Bass. https://doi.org/10.1002/9781118764282.ch7

[50] Biden JR (2021, January 21). Executive Order On Advancing Racial Equity and Support for Underserved Communities Through the Federal Government. The White House. https://www.whitehouse.gov/briefing-room/presidentialactions/2021/01/20/executive-order-advancing-racial-equity-and-support-forunderserved-communities-through-the-federal-government/

[51] Lincoln JR, Miller J (1979). Work and Friendship Ties in Organizations: A Comparative Analysis of Relation Networks. Administrative Science Quarterly 24(2):181-199. https://doi.org/10.2307/2392493

[52] Totterdell P, Wall T, Holman D, Diamond H, Epitropaki O. (2004). Affect Networks: A Structural Analysis of the Relationship Between Work Ties and Job-Related Affect. Journal of Applied Psychology 89(5):854-867. https://doi.org/10.1037/00219010.89.5.854

[53] Mehra A, Kilduff M, Brass DJ (2001). The Social Networks of High and Low SelfMonitors: Implications for Workplace Performance. Administrative Science Quarterly 46(1):121-146. https://doi.org/10.2307/2667127

[54] Rodan S, Galunic C (2004). More than Network Structure: How Knowledge Heterogeneity Influences Managerial Performance and Innovativeness. Strategic Management Journal 25(6):541-562. https://doi.org/10.1002/smj.398 
[55] Lazega E, Mounier L, Snijders T, Tubaro P (2012). Norms, Status and the Dynamics of Advice Networks: A Case Study. Social Networks 34(3):323-332. https://doi.org/ 10.1016/j.socnet.2009.12.001

[56] Sykes TA, Venkatesh V, Johnson JL (2014) University of Arkansas. Enterprise System Implementation and Employee Job Performance: Understanding the Role of Advice Networks. MIS Quarterly 38(1):51-72. https://doi.org/10.25300/MISQ/2014/38.1.03

[57] Gibbons DE (2004). Friendship and Advice Networks in the Context of Changing Professional Values. Administrative Science Quarterly 49(2):238-262. doi:10.2307/ 4131473

[58] Zagenczyk TJ, Murrell AJ (2009). It is Better to Receive than to Give: Advice Network Effects on Job and Work-Unit Attachment. Journal of Business and Psychology 24(2):139-152. https://doi.org/10.1007/s10869-009-9095-3

[59] Hill RA, Dunbar RIM (2003). Social Network Size in Humans. Human Nature 14(1):53-72. https://doi.org/10.1007/s12110-003-1016-y

[60] Ben-Nun P (2008). Respondent Fatigue. In P. J. Lavrakas (Ed.), Encyclopedia of Survey Research Methods (pp. 742-743). SAGE Publications, Inc.

[61] Marineau JE, Hood AC, Labianca G (2018). Multiplex Conflict: Examining the Effects of Overlapping Task and Relationship Conflict on Advise Seeking in Organizations. Journal of Business and Psychology 33(5):595-610. https://doi.org/10.1007/ s10869-017-9511-z

[62] Nebus J (2006). Building Collegial Information Networks: A Theory of Advice Network Generation. Academy of Management Review 31(3):615-637. https://doi.org/10. 5465/amr.2006.21318921

[63] Brooks AW, Gino F, Schweitzer ME (2015). Smart People Ask for (My) Advice: Seeking Advice Boosts Perceptions of Competence. Management Science 61(6):1421-1435. https://doi.org/10.1287/mnsc.2014.2054

[64] Bento F, Tagliabue M, Lorenzo F (2020). Organizational Silos: A Scoping Review Informed by a Behavioral Perspective on Systems and Networks. Societies 10(3):127. https://doi.org/10.3390/soc10030056

[65] McPherson M, Smith-Lovin L, Cook JM (2001). Birds of a Feather: Homophily in Social Networks. Annual Reviews of Sociology 27(1):415-444. https://doi.org/10. 1146/annurev.soc.27.1.415

[66] Warren PY, Farrell A. (2009) The Environmental Context of Racial Profiling. The ANNALS of the American Academy of Political and Social. Science 623(1):52-63. doi:10.1177/0002716208330485

[67] Zwolak JP, Zwolak M, Brewe E (2018) Educational Commitment and Social Networking: The Power of Informal Networks. Phys. Rev. Phys. Educ. Res. 14:010131. https://link.aps.org/doi/10.1103/PhysRevPhysEducRes.14.010131

[68] Hlebec V (1993) Recall Versus Recognition: Comparison of the Two Alternative Procedures for Collecting Social Network Data. In Developments in Statistics and Methodology (eds Ferligoj A and Kramberger A) Metodološki zvezki. 9. (pp. 121-128) https://www.researchgate.net/publication/264893988_Recall_Versus_ 
Recognition_Comparison_of_the_Two_Alternative_Procedures_for_Collecting_ Social_Network_Data

[69] Nelson A, Piatak J (2019). Intersectionality, Leadership, and Inclusion: How Do Racially Underrepresented Women Fare in the Federal Government? Review of Public Personnel Administration https://doi.org/10.1177/0734371X19881681

[70] Tsui A, O'reilly CA (1989). Beyond Simple Demographic Effects: The Importance of Relational Demography in Superior-Subordinate Dyads. The Academy of Management Journal 32(2):402-423. https://www.jstor.org/stable/256368 


\section{Appendix: Supplemental Materials}

\section{Question A: Who do you interact with most frequently to achieve your work goals at NIST?}

Please take a piece of paper and write down the names of NIST colleagues that come to mind for Question A. Focus on those with whom you have interacted most frequently over the last six months. Please include people that have specific expertise that you rely on to do your work or who provide you with important information or resources. Please be sure to consider both people in your immediate team as well as people outside of your team with whom you frequently collaborate. Please list at least three people. When you are done writing the names associated with this question, please label the first person on your list as "Person 1" and so on. Then, proceed to the next section.

Did you finish writing the list of names for Question A? *

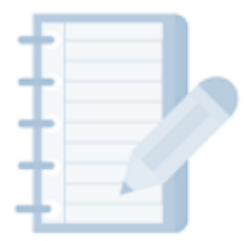
$\bigcirc$ Yes
No

Back

Next

Fig. A1. Network question A. 


\section{Question B: Who do you go to for advice when making important career-related decisions at NIST?}

Please take a piece of paper and write down the names of NIST colleagues that come to mind for Question B. Focus on those who you think of when you need coaching or information to assist you through an unforeseen situation at NIST. Please be sure to include people who may inspire you and those with whom you discuss new ideas. Please consider those who may help you navigate through career advancement, or provide high visibility opportunities for you, or advocate a promotion for you. You may select anyone in the organization, including people that you have previously listed. When you are done writing the names associated with this question, please label the first person on your list as "Person 1" and so on. Then, proceed to the next section.

Did you finish writing the list of names for Question B? *

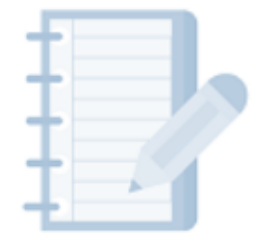
$\bigcirc$ Yes
No

Back

Next

Fig. A2. Network question B. 


\section{NLT \\ National Institute of \\ Standards and Technology \\ U.S. Department of Commerce}

October 16, 2020

\section{MEMORANDUM FOR Laura Espinal \\ Principal Investigator}

From: Anne Andrews

Director, Research Protections Office

Subject: Determination for Project \#MR-2020-0237 entitled, "NIST Interactions Survey for Inclusivity Network Analysis"

The above referenced proposed project was submitted to the Research Protections Office (RPO), and determined to meet the criteria for exempt human subjects research as defined in Department of Commerce Regulations, 15 CFR 27, also known as the Common Rule for the Protection of Human Subjects (45 CFR 46, Subpart A). The Principal Investigator is administering a survey to determine NIST Federal employees networks and group dynamics. Participants will be asked to complete an online survey regarding their demographics and those they interact with on the NIST campus.

This project meets the criteria in (15 CFR 27.104(d)(2)) Research that only includes interactions involving educational tests (cognitive, diagnostic, aptitude, achievement), survey procedures, interview procedures, or observation of public behavior (including visual or auditory recording) if at least one of the following criteria is met:

i. The information obtained is recorded by the investigator in such a manner that the identity of the human subjects cannot readily be ascertained, directly or through identifiers linked to the subjects;

ii. Any disclosure of the human subjects' responses outside the research would not reasonably place the subjects at risk of criminal or civil liability or be damaging to the subjects' financial standing, employability, educational advancement, or reputation;

iii. Or the information obtained is recorded by the investigator in such a manner that the identity of the human subjects can readily be ascertained, directly or through identifiers linked to the subjects, and an IRB conducts a limited IRB review to make the determination required by .111(a)(7). This determination was based on reviewing the following documents:

\begin{tabular}{|l|l|l|}
\hline Submission Components & Outcome \\
\hline Form Name & Version & Approved \\
\hline Review Response Form - IRB & Version 1.0 & Approved \\
\hline Initial Review Submission Packet & Version 1.0 & Approved \\
\hline NIST Internal Application & Version 1.1 \\
\hline \multicolumn{2}{|l}{} \\
\hline Study Document
\end{tabular}

Fig. A3. Approval letter from the NIST Research Protections Office (Page 1 of 2). 


\section{NGT}

National Institute of

Standards and Technology

U.S. Department of Commerce

\begin{tabular}{|l|l|l|l|}
\hline Title & Version \# & Version Date & Outcome \\
\hline $\begin{array}{l}\text { Attachment 2 - } \\
\text { NIST_Interactions_Survey_100620v1 }\end{array}$ & Version 1.1 & $10 / 06 / 2020$ & $\begin{array}{l}\text { Acknowledge } \\
\text { d }\end{array}$ \\
\hline IT Security Email & Version 1.0 & $10 / 06 / 2020$ & $\begin{array}{l}\text { Acknowledge } \\
\text { d }\end{array}$ \\
\hline $\begin{array}{l}\text { Table of Associates Data requested from } \\
\text { NAIS }\end{array}$ & Version 1.0 & $10 / 06 / 2020$ & $\begin{array}{l}\text { Acknowledge } \\
\text { d }\end{array}$ \\
\hline $\begin{array}{l}\text { Attachment 1 - Table HR data } \\
\text { needed_091020v1 }\end{array}$ & Version 1.0 & $09 / 16 / 2020$ & $\begin{array}{l}\text { Acknowledge } \\
\text { d }\end{array}$ \\
\hline \multicolumn{2}{|l|}{} \\
\hline Study Consent Form & Version \# & Version Date & Outcome \\
\hline Title & Version 1.1 & $10 / 06 / 2020$ & Approved \\
\hline \begin{tabular}{l} 
Information_Sheet_NIST_Interactions_Survey \\
\hline
\end{tabular} & & \\
\hline
\end{tabular}

This determination is valid only for this project. You are responsible for conducting this project as outlined in the above documents. Any future uses of the data must be submitted to RPO as a new protocol.

You are responsible for providing an Annual Report via iMedRIS before . The reminder for the Annual Report will be automatically sent to you from iMedRIS several times in advance of the due date, which is 30 days before the expiration date. If the study concludes before then, please submit an Annual Report early through iMedRIS, which includes the option to transmit your closure report to the RPO.

This project may proceed with no further requirement for review by the RPO, but may require other required agreements, grant, contract and/or OU approvals. In the event that there is a change to the abovedescribed project that may affect its determination status, send a description of the change to the RPO. The RPO will re-evaluate the project, if necessary.

You are responsible for keeping other NIST offices, (e.g., purchasing, technology transfer, etc.), and external collaborators informed about this determination or any approved changes to the project.

Signature applied by Anne M Andrews on 10/16/2020 10:10:49 AM EDT

Fig. A4. Approval letter from the NIST Research Protections Office (Page 2 of 2). 


\section{NIST Interactions Survey}

Welcome to the NIST Interactions Survey!

This is your opportunity to share information about your perceived interactions with other members of the NIST workforce to help NIST leaders determine the next steps towards assessing the current level of inclusivity at NIST so we can track improvements.

This research survey takes approximately 20 minutes.

You will be asked two network questions. Because we will not ask you to provide your name or the name of your colleagues, we recommend that you get a piece of paper before you enter the next page. In that way, you can write down the names that come to mind for each network question and keep track of the answers yourself.

We appreciate your time and input!

This survey is only for NIST Federal employees. You must be at least 18 years old to participate. Your Participation is Confidential and Voluntary. By continuing you are consenting to participate in this research.

An information sheet describing the survey can be found in the NIST internal website: https://inet.nist.gov/system/files/documents/2020/10/28/information.pdf

Click NEXT to take the survey!

* Required

Fig. A5. Welcome page for the NIST Interactions Survey with a link to information sheet and brief instructions. 


\section{NIST Interactions Survey}

* Required

Did you list more than 3 people for Question A? *
$\bigcirc$ Yes
No

\section{Back Next}

Fig. A6. Skip logic used for Question A. The same skip logic was used for Question B. 
Dear Colleagues,

As part of NIST's continuing growth in inclusivity as our core value, the NIST leadership team and I are fully committed to advancing equity, diversity and inclusivity for all at NIST. As part of that effort, we announced three gender equity projects last fall, and these have been progressing well.

Your input is vital to the success of each of these projects and so I am once again asking for your participation in an anonymous survey to support this important work.

The questions will differ from the previous survey and will provide a different picture of the experiences of federal employees at NIST, this time focusing on personal networks. Your responses will help us understand how staff interact within and across OUs and how those interactions might differ according to gender, race and work history. This survey will also provide a baseline we can use to track the impact of our efforts to increase inclusivity.

Please keep an eye out for the NIST Interactions Survey, which will be sent to all NIST federal employees and will be open for a three-week period. Once it is made available, please join us on this journey to continue improving the equity, diversity and inclusion of the NIST workforce.

Warm regards,

Walt Copan

NIST Director

Fig. A7. Survey announcement. Announcement from the NIST Director alerting staff about the NIST Interactions Survey coming soon. 


\section{NLT: \\ U.S. Department of Commerce}

Dear NIST Federal Employee,

You are invited to participate in the NIST Interactions Survey! This is a survey that's unlike any other to which you have responded before - and I hope you will invest a few minutes of your time to complete it. Your anonymous responses will serve as a critically important part of Dr. Laura Espinal's research designed to identify perceptions across NIST about interactions with other members of the NIST workforce, and to help understand how the wide range of NIST networks of collaboration, mentorship and trust function. This effort is intended to help NIST leaders determine the next steps towards assessing the current level of inclusivity at NIST so we can continue to improve.

The research is being performed as part of a detail project on Inclusivity Network Analysis awarded by the Associate Director for Laboratory Programs and jointly sponsored by the Office of Human Resources Management (OHRM) and the Steering Group for Equity in Career Advancement (SGECA) to study aspects of equity, diversity, and inclusion in the NIST community.

An information sheet describing the survey (PDF) is available on the NIST internal website.

Please click the link below and provide your answers by Wednesday, November 25, 2020. Your input is important. Survey responses are entirely anonymous, and it should take less than 20 minutes to complete. Consider this time well invested in a better future for all NISTers.

Here is your personalized link, to be used only by you: Click here to access your survey

Please join us on this part of our journey to continue improving the equity, diversity and inclusivity of the NIST workforce.

Warm regards,

Walt Copan

NIST Director

Fig. A8. Email invitation sent to NIST Federal Employees with the link to the NIST Interactions Survey. 


\section{NGT}

Announcement

inet.nist.gov

Dear NIST Colleagues,

I urge you to respond to the NIST Interactions Survey, which was sent on November 4th to all Federal staff at NIST.

The survey has been designed to provide greater insight into our core value of inclusivity. Your anonymous responses will provide a picture of the perceptions across NIST about interactions with other members of the NIST workforce. This study also is designed to help us all understand how the wide range of NIST networks of collaboration, mentorship and trust are functioning, and how they might be enhanced in the future.

All eligible NIST Federal Employees who have been working at NIST as of October 10, 2020 should have received an email from me (sent via "donotreply@nist.gov") on Wednesday, November 4, 2020. That message contains a unique link for you to access the survey. If you did not see the email, please also check your junk/spam folder. The survey will be open until Wednesday, November 25.

NIST's leadership is committed to our values of excellence, inclusivity, integrity and perseverance. As we continue to strengthen our culture of inclusivity, we need your inputs to ensure that this Interactions Survey fully represents our NIST employees.

Thank you for your contribution to our self-assessment - and to a constantly better ONE NIST.

Walt Copan

NIST Director

Fig. A9. Final email from the NIST Director reminding staff about the NIST Interactions Survey closing soon. 
Table A1. List of demographic and work history questions about the ego.

\begin{tabular}{|c|c|}
\hline Question & Drop-down choices \\
\hline \multirow[t]{4}{*}{ You identify yourself as: } & Female \\
\hline & Male \\
\hline & Non-binary \\
\hline & Prefer not to answer \\
\hline \multirow{2}{*}{$\begin{array}{l}\text { Which ethnic/racial cate- } \\
\text { gory do you identify } \\
\text { with? }\end{array}$} & $\begin{array}{l}\text { Minority (American Indian, Asian, Black, Hispanic, Native Hawai- } \\
\text { ian, Other) }\end{array}$ \\
\hline & Non-minority (White) \\
\hline \multirow[t]{5}{*}{ What is your birth year? } & Born 1945 or earlier \\
\hline & Born between 1946 and 1964 \\
\hline & Born between 1965 and 1980 \\
\hline & Born between 1981 and 1996 \\
\hline & Born 1997 or later \\
\hline \multirow{2}{*}{$\begin{array}{l}\text { Are you a supervisor or } \\
\text { manager? }\end{array}$} & Yes \\
\hline & No \\
\hline \multirow{4}{*}{$\begin{array}{l}\text { How many years have } \\
\text { you worked at NIST? }\end{array}$} & Less than 4 years \\
\hline & Between 4 and 10 years \\
\hline & Between 11 and 20 years \\
\hline & More than 20 years \\
\hline \multirow{3}{*}{$\begin{array}{l}\text { You are affiliated with the } \\
\text { NIST site in: }\end{array}$} & Colorado \\
\hline & Maryland \\
\hline & Other \\
\hline \multirow{19}{*}{$\begin{array}{l}\text { Your Organizational Unit } \\
\text { (OU) is: }\end{array}$} & BPEP (Baldrige Performance Excellence Program) \\
\hline & CTL (Communications Technology Laboratory) \\
\hline & DO (Director's Office) \\
\hline & EL (Engineering Laboratory) \\
\hline & HMEPP (Hollings Manufacturing Extension Partnership Program) \\
\hline & IIS (Innovation and Industry Services) \\
\hline & ITL (Information Technology Laboratory) \\
\hline & LP (Laboratory Programs) \\
\hline & MML (Material Measurement Laboratory) \\
\hline & MR (Management Resources) \\
\hline & NCNR (NIST Center for Neutron Research) \\
\hline & OAAM (Office of Acquisition and Agreements Management) \\
\hline & OAM (Office of Advanced Manufacturing) \\
\hline & OFPM (Office of Facilities and Property Management) \\
\hline & OFRM (Office of Financial Resource Management) \\
\hline & OHRM (Office of Human Resources Management) \\
\hline & OSHE (Office of Safety, Health and Environment) \\
\hline & OISM (Office of Information Systems Management) \\
\hline & PML (Physical Measurement Laboratory) \\
\hline
\end{tabular}


Table A2. List of demographic and work history questions about the alters. The same questions about each alter were asked for both Question A and B. The $N$ circulated through numbers 1 to (at most) 9 .

\begin{tabular}{ll}
\hline Question & Drop-down choices \\
\hline Person $N$ identifies as: & Female \\
& Male \\
& Non-binary \\
& I don't know or prefer not to answer \\
\hline Compared to you, & Younger (more than 10 years) \\
Person $N$ is: & Similar \\
& Older (More than 15 years) \\
\hline Is Person $N$ a supervisor & Yes \\
or manager (not necessar- & No \\
ily yours)? & \\
\hline Person $N$ is affiliated with & Colorado \\
the NIST site in: & Maryland \\
& Other \\
\hline Person $N$ is affiliated with & BPEP (Baldrige Performance Excellence Program) \\
the following OU at NIST & CTL (Communications Technology Laboratory) \\
& DO (Director's Office) \\
& EL (Engineering Laboratory) \\
& HMEPP (Hollings Manufacturing Extension Partnership Program) \\
& IIS (Innovation and Industry Services) \\
& ITL (Information Technology Laboratory) \\
& LP (Laboratory Programs) \\
& MML (Material Measurement Laboratory) \\
& MR (Management Resources) \\
& NCNR (NIST Center for Neutron Research) \\
& OAAM (Office of Acquisition and Agreements Management) \\
& OAM (Office of Advanced Manufacturing) \\
& OFPM (Office of Facilities and Property Management) \\
& OFRM (Office of Financial Resource Management) \\
& OHRM (Office of Human Resources Management) \\
& OSHE (Office of Safety, Health and Environment) \\
& OISM (Office of Information Systems Management) \\
& PML (Physical Measurement Laboratory) \\
\hline \hline & \\
& \\
\hline &
\end{tabular}

